\title{
Identification and Quantification of Copper Sites in Zeolites by Electron Paramagnetic Resonance Spectroscopy
}

\author{
Godiksen, Anita; Vennestrøm, Peter N. R.; Rasmussen, Søren Birk; Mossin, Susanne
}

Published in:

Topics in Catalysis

Link to article, DOI:

10.1007/s11244-016-0731-7

Publication date:

2017

Document Version

Peer reviewed version

Link back to DTU Orbit

Citation (APA):

Godiksen, A., Vennestrøm, P. N. R., Rasmussen, S. B., \& Mossin, S. (2017). Identification and Quantification of Copper Sites in Zeolites by Electron Paramagnetic Resonance Spectroscopy. Topics in Catalysis, 60(1), 13-29. https://doi.org/10.1007/s11244-016-0731-7

\section{General rights}

Copyright and moral rights for the publications made accessible in the public portal are retained by the authors and/or other copyright owners and it is a condition of accessing publications that users recognise and abide by the legal requirements associated with these rights.

- Users may download and print one copy of any publication from the public portal for the purpose of private study or research.

- You may not further distribute the material or use it for any profit-making activity or commercial gain

- You may freely distribute the URL identifying the publication in the public portal 


\title{
Mini-review: \\ Identification and quantification of copper sites in zeolites by electron paramagnetic resonance spectroscopy
}

\author{
Anita Godiksen ${ }^{1}$, Peter N. R. Vennestrøm ${ }^{2}$, Søren B. Rasmussen ${ }^{2}$, Susanne Mossin ${ }^{1}{ }^{*}$ \\ ${ }^{1}$ Technical University of Denmark, Kemitorvet 207, 2800 Kgs. Lyngby, Denmark \\ ${ }^{2}$ Haldor Topsøe, Nymøllevej 55, 2800 Kgs. Lyngby, Denmark \\ *slmo@kemi.dtu.dk
}

Tel: +45 45252391

\section{Acknowledgements.}

This work was financially supported by the Danish Independent Research Council DFF - 1335-00175. The Carlsberg Foundation is acknowledged for supporting the upgrade of the EPR instrument at DTU Chemistry. 


\begin{abstract}
Recent quantitative electron paramagnetic resonance spectroscopy (EPR) data on different copper species present in copper exchanged in CHA zeolites are presented and put into context with the literature on other copper zeolites. The information were obtained using $e x$-situ and in-situ EPR on copper ion exchanged into a CHA zeolite with $\mathrm{Si} / \mathrm{Al}=14 \pm 1$ to obtain $\mathrm{Cu} / \mathrm{Al}$ $=0.46 \pm 0.02$. The results shed light on the identity of different copper species present after activation in air. Since the EPR signal is quantifiable, the content of the different $\mathrm{EPR}$ active species has been elucidated and $\mathrm{Cu}^{2+}$ in $2 \mathrm{Al}$ positions in the 6membered rings (6mr) of the CHA structure has been characterized. Some copper species are found not to give an EPR signal at ambient or high temperatures. Fortunately treatments with different gasses under in-situ conditions are able to trigger an EPR signal and thus reveal information about the reactivity and the quantity of some of the otherwise EPR silent species. In this way the $[\mathrm{Cu}-\mathrm{OH}]^{+}$species in copper substituted low-Al zeolites has been indirectly observed and quantified. EPR active $\mathrm{Cu}^{2+}$ species have been followed under reduction and oxidation with gas mixtures relevant for the selective catalytic reduction of $\mathrm{NO}$ with $\mathrm{NH}_{3}\left(\mathrm{NH}_{3}\right.$-SCR) revealing that all $\mathrm{Cu}^{2+}$ in $6 \mathrm{mr}$ are easily reduced and oxidized at $200^{\circ} \mathrm{C}$. Furthermore a stable [Cu- $\left.\mathrm{NO}_{3}\right]^{+}$species is identified in $\mathrm{Cu}-\mathrm{CHA}$ after exposure to $\mathrm{NO}$ and $\mathrm{O}_{2}$, but is not stable in $2 \mathrm{Al} 6 \mathrm{mr}$ sites of the CHA structure under the applied conditions.
\end{abstract}

Keywords: environmental catalysis, selective catalytic reduction, Cu-CHA, in-situ spectroscopy, electron paramagnetic resonance 


\section{Introduction}

Copper exchanged zeolites have proven to be excellent catalysts for the selective catalytic reduction (SCR) of nitrogen oxides $\left(\mathrm{NO}_{\mathrm{x}}=\mathrm{NO}\right.$ and $\left.\mathrm{NO}_{2}\right)$ from exhaust gases using ammonia as a reductant $\left(\mathrm{NH}_{3}\right.$-SCR). The $\mathrm{NH}_{3}$-SCR reaction using copper zeolites currently attract both fundamental and practical interest due to the growing application and need for automotive diesel exhaust treatment systems. This is one of the fastest growing catalytic applications of zeolite materials.

Especially copper exchanged zeolites and zeotypes with the CHA framework topology has received significant interest over the last years due to enhanced hydrothermal stability, high tolerance towards hydrocarbons and limited selectivity towards unwanted nitrous oxide $\left(\mathrm{N}_{2} \mathrm{O}\right)$ [1-3]. Combustion of hydrocarbons in a diesel engine running under lean conditions (fuelefficient) is one of the main contributors to $\mathrm{NO}_{\mathrm{x}}$ pollution. Approximately $40 \%$ of the total $\mathrm{NO}_{\mathrm{x}}$ emitted in the EU originates from road transport and hereof diesel engines accounts for $75 \%$ [4]. To reduce the $\mathrm{NO}_{\mathrm{x}}$ emission legislation is applying strict limits on the automotive emissions, and since 2005 after-treatment systems have been required to increase their efficiency in order to concur with the increasingly more stringent limits. Another large $\mathrm{NO}_{\mathrm{x}}$ emitter is the marine industry that is using heavy diesel engines and will be subject to more strict emission legislation in the foreseeable future. One of the most promising strategies to concur with current and future limits is to use $\mathrm{NH}_{3}-\mathrm{SCR}$ catalysis.

Different copper and iron exchanged zeolites have been investigated as catalysts for $\mathrm{NH}_{3}$-SCR over the years and have been characterized by a broad range of methods including electron paramagnetic resonance spectroscopy (EPR). In this minireview we will focus on copper exchanged into the large pore zeolites $\mathrm{Y}$, Mordenite and Beta with the FAU, MOR and *BEA framework topologies; medium pore zeolite ZSM-5 with the MFI framework topology, and finally the small pore zeolite SSZ-13 with the CHA framework topology [5].

$\mathrm{Cu}-\mathrm{FAU}$ was the first copper exchanged zeolite to receive interest as a catalyst for $\mathrm{NH}_{3}$-SCR due to the wide spread availability of Y zeolite, which is extensively used in the oil industry. However, it exhibited very fast deactivation and was quickly discarded for application in $\mathrm{NH}_{3}$-SCR. Nevertheless much effort has been put into the characterization of this catalyst. In 1991 Iwamoto and Hamada found Cu-MFI to be a promising catalyst the direct decomposition of NO and SCR with hydrocarbons[6]. For this reason it was also studied extensively and also adapted for $\mathrm{NH}_{3}$-SCR applications. Cu-MFI proved to be more active than $\mathrm{Cu}-\mathrm{FAU}$, but it still lacked hydrothermal stability. Later $\mathrm{Cu}-{ }^{*} \mathrm{BEA}$ were considered, but hydrothermal stability remained an issue. Later $\mathrm{Cu}-\mathrm{CHA}$ was the first material to provide sufficient stability for current requirements and has been shown to also yield high activity and selectivity [2, 7].

$\mathrm{Cu}-\mathrm{CHA}$ has been under investigation since the late 00's and characterization of the $\mathrm{Cu}$-species located in extra-framework positions in the CHA zeolite has been extensively studied within the last years. The accumulated characterization data obtained can now be used to obtain a more comprehensive picture of the different copper species. During the last year, a number of studies on the mechanism for the $\mathrm{NH}_{3}$-SCR on Cu-CHA have also been published [8-10]. This mini-review collects the spectroscopically distinct copper sites in $\mathrm{Cu}$ exchanged zeolites proposed in literature with a special interest in those characterized by EPR spectroscopy. EPR is a powerful tool to analyze the nature of $\mathrm{Cu}^{2+}$ species, and is able to give 
information on the oxidation state and coordination of the EPR active copper sites. It is revealed that when the EPR parameters of the different $\mathrm{Cu}$ sites of dehydrated $\mathrm{Cu}$ zeolites are plotted towards each other they all fall on a single trend line, the differences between sites being correlated to the charge of the donor atoms coordinating to $\mathrm{Cu}$. In addition, the double integral of the EPR spectrum can provide quantitative information on the total amount of EPR active copper species and the distribution of different copper species present. Finally, recent results of investigation of the SCR reaction[8] will be briefly reviewed. The experimental in-situ EPR results have implications for the discussion of Cu sites present under SCR gasses that were not touched upon before. This discussion will be included here.

\section{Experimental section}

The Cu-zeolite materials investigated by us (Cu-CHA, Cu-MFI, Cu-*BEA) have been described in the literature [8, 11-13] Briefly, all Cu-zeolites were prepared by aqueous exchange with copper(II)acetate of the proton- or ammonium form of the parent zeolite to obtain the desired Cu-exchange degree. Calcination at $500{ }^{\circ} \mathrm{C}$ removes all traces of ammonia/ammonium and acetate/acetic acid, leaving only protons and copper ions. Parent zeolites were chosen to have similar Si/Al ratios and $\mathrm{Cu} / \mathrm{Al}$ ratios. For $\mathrm{Cu}-\mathrm{CHA} \mathrm{Si} / \mathrm{Al}=14 \pm 1$ and $\mathrm{Cu} / \mathrm{Al}=0.46 \pm 0.02$, which amounts to approximately $2.5 \mathrm{wt} \% \mathrm{Cu}$.

A description of the in-situ EPR setup used for the investigations can be found in[12].

\section{EPR of copper containing materials}

Continuous wave EPR spectroscopy is not very demanding with respect to the sample preparation and it is possible to fit a 4 $\mathrm{mm}$ inner diameter linear plug-flow reactor into the cavity of the instrument and still have room for an outer tube guiding a controllable flow of heated air to heat the reactor. EPR is very sensitive and can easily detect EPR active $\mathrm{Cu}^{2+}$ species in zeolites in 1-100 mg samples of $\mathrm{Cu}$ zeolites with $\mathrm{Cu}$ concentrations relevant to $\mathrm{NH}_{3}$-SCR or even at concentrations which are a fraction of that. It is possible to collect spectra with a time resolution of down to about $15 \mathrm{~s}$ in the relevant field range, but if the highest possible time resolution is not needed, spectra are usually collected continuously with a time resolution of about $45 \mathrm{~s}$.

Examples of EPR spectra of $\mathrm{Cu}^{2+}$ are shown in Fig. 1. The spectrum on the left shows a simulated spectrum of Cu-CHA with two different $\mathrm{Cu}$ sites which are sufficiently different to be resolved. It is indicated on the figure where an estimate of the characteristic parameters can be read of the spectrum.

The experimental EPR spectra are fitted using computer software [14] to obtain the parameters with higher precision. The computer simulations are performed by solving a spin Hamiltonian, Eq. 1 to find the field values and orientations of the crystallites for which the spin transition matches the energy of the microwave radiation. 


$$
H=g_{\|} \mu_{B} S_{z} B_{z}+g_{\perp} \mu_{B}\left(S_{x} B_{x}+S_{y} B_{y}\right)+A_{\|} S_{z} I_{z}+A_{\perp}\left(S_{x} I_{x}+S_{y} I_{y}\right)
$$

The parameters in the model for an axial $\mathrm{Cu}^{2+}$ system are the g-values $g_{\|}\left(=g_{z}\right)$ and $g_{\perp}\left(=g_{x}=g_{y}\right)$ and the hyperfine coupling constants, $A_{\|}$and $A_{\perp} \cdot \mu_{B}$ is the Bohr magneton, $B_{z}, B_{x}$ and $B_{y}$ are the components of the magnetic field, $S_{z}, S_{x}$ and $S_{y}$ are the components of the electronic spin operator and $I_{z}, I_{x}$ and $I_{y}$ are components of the nuclear spin operator. Additional parameters which are used in the fit to obtain the shape of the experimental spectrum are the line shape (which is chosen as gaussian) and line width parameters. It is assumed that the g and A tensors are collinear to simplify the model.

Both naturally occurring copper isotopes have $I=3 / 2$ and this splits the lines of the EPR spectrum into 4 hyperfine lines. Only the splitting in the z-direction is large enough to be visible. The difference between the two Cu isotopes is included in the simulation program but the effect is not resolved at the line widths observed for Cu zeolite materials.

If the main axis of the system changes faster than the time scale of the experiment, then the difference between the $\mathrm{z}$ axis and the two other axes cannot be detected and the resulting spectrum will be isotropic and centered at a g-value, which is an average of the g-values corresponding to the three axes $\left(g_{\|}, g_{\perp}\right.$ and $\left.g_{\perp}\right)$. The spectrum will be split by the interaction of the unpaired electron with the nucleus by a value, which is an average of the three A-values. In the experimental spectrum of hydrated $\mathrm{Cu}-\mathrm{CHA}$ shown to the right in Fig. 1 features recognizable as an isotropic $\mathrm{Cu}^{2+}$ EPR spectrum as well as an anisotropic $\mathrm{Cu}^{2+} \mathrm{EPR}$ spectrum are seen.

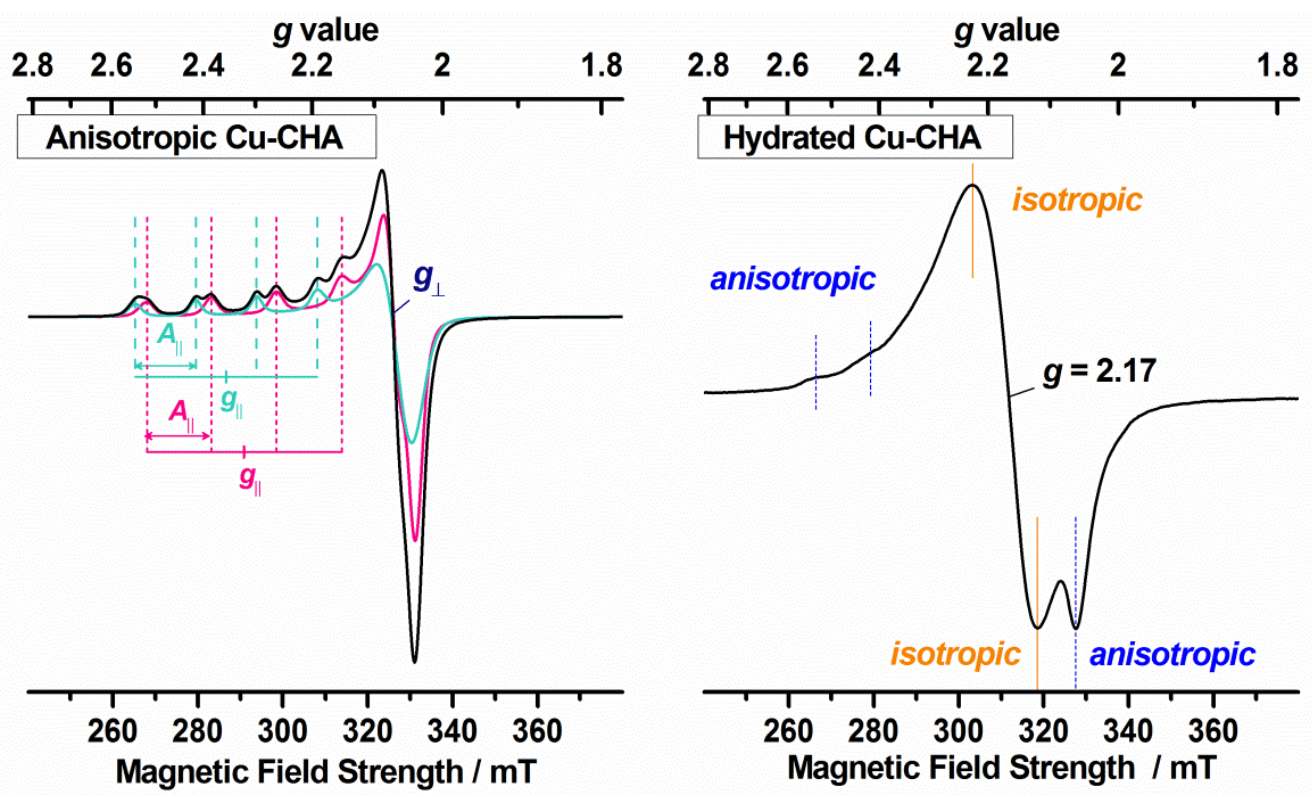

Fig. 1 Left: Calculated anisotropic spectrum (black) for two monomeric $\mathrm{Cu}^{2+}$ species with the parameters found for EPR signal 1 and 2 in a dehydrated Cu-CHA sample. The spectrum is found as a simple sum of the spectra for each species, which are shown in pink for signal 1 and in teal for signal 2. The values used in the simulation are given in Table 1 . The characteristic splitting of the line centered at $g_{\|}$due to the interaction with the copper nucleus is indicated for each species. Right: Experimental spectrum obtained at room temperature 
without flow for a $\mathrm{Cu}-\mathrm{CHA}$ sample $(\mathrm{Si} / \mathrm{Al}=14, \mathrm{Cu} / \mathrm{Al}=0.46)$. Features assigned to an anisotropic $\mathrm{Cu}^{2+}$ species and to an isotropic $\mathrm{Cu}^{2+}$ species is indicated with blue and orange lines, respectively.

The spectra given are all first derivatives of the absorption spectra and in order to obtain the intensity of an EPR spectrum the spectrum has to be integrated twice. The amplitude of the response of one unpaired electron to an external field is quantifiable when compared to a known standard. In this way the EPR-active $\mathrm{Cu}^{2+}$ centers can be quantified and compared to the total amount of $\mathrm{Cu}$ present in the sample as determined by elemental analysis. The method is very precise (uncertainties less than a few \%) towards comparing values throughout an experiment if sufficient care is taken to hold temperature, sample position, Q-factor of the cavity, baseline etc. constant. It is also possible to compare with reference materials measured under the same conditions, but this is connected with a higher uncertainty. It is normally considered to be precise within around $\pm 20 \%$ if the experiments are conducted carefully and if the correction for the baseline is good.

The resolution of the different $\mathrm{Cu}$ species in dehydrated materials is possible due to a reasonably low line width. The following factors are suggested to keep the line width low: Even though the materials are highly exchanged (approaching $\mathrm{Cu} / \mathrm{Al}=0.5$ ), a high $\mathrm{Si} / \mathrm{Al}$ ratio ensures that the concentration of $\mathrm{Cu}$ in the material is low enough to keep the individual $\mathrm{Cu}^{2+}$ centers magnetically isolated. An improvement in the line width is observed when measuring under a flow of helium since paramagnetic dioxygen and NO are excluded. Specifically for the Cu-CHA material described in [12] the well-defined structure improves the resolution: The CHA zeolite is structurally simpler than most other zeolites and the narrow distribution of sites give sharper lines. Furthermore, the CHA synthetic material investigated were prepared by the fluoride route which is known to give a low number of structural defects compared to other synthesis methods [11].

Several groups have shown that the hyperfine coupling parameters and the g-values found for a particular copper ion will vary depending on the surrounding ligand field [15-17]. The deviation of the g-values for a Cu site from the free electron gvalue of 2.0023 depends on the degree of mixing with close-lying excited d-d states. To the first order it is proportional to the spin-orbit coupling constant, $\lambda$, and inversely proportional to the ligand field splitting parameter, $\Delta$. The hyperfine constants depend on the electron spin density felt at the $\mathrm{Cu}$ nuclei. These effects are phenomenologically found to work together in such a way that for $\mathrm{Cu}$ complexes with similar coordination environment, the least negative charge on the coordination environment and lower ligand field splitting parameter, $\Delta$ will be the species with a higher $g_{\|}$and lower $A_{\|}$and that the sets of parameters describe an approximately straight line. This empirical correlation was described in 1974 for

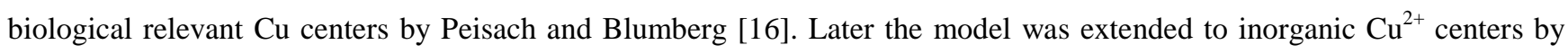
Sakaguchi and Addison [17], revealing the impact of the immediate coordination sphere and confirming that an increase in total charge on the copper complex correspond to a low $A_{\|}$and high $g_{\|}$. The models have proven very useful for copper exchanged zeolites $[18,19]$.

$\mathrm{Cu}^{2+}$ is a $\mathrm{d}^{9}$ system and will have an unpaired electron and therefore a spin doublet ground state. Normally the system adopts a square planar or axially elongated tetragonal coordination environment. In this case the ground state is non- 
degenerate and the nearest electronically excited state is relatively far away: $\left(>10000 \mathrm{~cm}^{-1}\right)$ and the interaction with the ground state is modest. In certain high-symmetric coordination environments, the system will have an orbital degeneracy as described below. This situation is not stable and any distortion giving a non-degenerate ground state will result in a system with a lower energy since a fully occupied orbital is stabilized at the expense of an orbital which is only half-filled. This is known as the Jahn-Teller effect [20, 21]. In some cases the ground state of the system is non-degenerate, but with closelying excited states since none of the possible geometric distortions is able to separate the ground state effectively. In this case effects on the spectroscopic response of the system can become evident. This is known as the pseudo Jahn-Teller effect. When excited states are close and the symmetries are compatible, the coupling between electronic states and vibronic states can become effective and may influence the lifetime of any excited electronic states of the $\mathrm{d}^{9}$ system. In EPR spectroscopy a different spin state is reached by resonant absorption of microwave radiation. In order for the event to be detected the excited state has to have a certain lifetime. If the spin-lattice relaxation rate described by the lifetime parameter, $T_{1}$ is too fast compared to the EPR frequency, which is around $10 \mathrm{GHz}$ for X-band EPR, then the transition is broadened and can become undetectable.

Assuming that all ligands are similar sigma donors the problem of near-degenerate ground states is an issue for $\mathrm{Cu}^{2+}$ in the following highly symmetric geometries: Octahedral, tetrahedral, trigonal bipyramidal and trigonal planar. An elongation or compression along a $\mathrm{C}_{4}$ axis of an octahedral coordination is very efficient in isolating the ground state and indeed tetragonal elongation is the situation normally observed. In the limit of infinite elongation square planar coordination is obtained and this is a quite normal coordination environment for copper as well. On the other hand a distortion along a $\mathrm{C}_{3}$ axis of an octahedron will not help in splitting the $\mathrm{E}_{\mathrm{g}}$ ground state. For a tetrahedron a compression along the $\mathrm{S}_{4}$ axis (towards square planar coordination) is very efficient towards obtaining a non-degenerate ground state whereas an elongation helps but is not as efficient. Elongation along a $\mathrm{C}_{3}$ axis does not lift the degeneracy at all and compression only helps in the limit of a very short axial bond which is not reasonable for $\mathrm{Cu}^{2+}$. Trigonal bipyramidal coordination has the same issue and elongation along the $\mathrm{C}_{3}$ axis will not split the ground state, which is still degenerate even in the limit of a trigonal planar coordination. Axial compression along the $\mathrm{C}_{3}$ axis can result in a non-degenerate ground state if the difference between the donor strength of the axial and equatorial donors are sufficiently high [22, 23].

$\mathrm{Cu}^{2+}$ in tetragonally distorted 5- or 6-coordination is the usual coordination environment for $\mathrm{Cu}^{2+}$ surrounded by oxygen atoms. It has an energetically well-separated ground state and this is the reason that EPR can be used to probe these $\mathrm{Cu}^{2+}$ species at ambient conditions or even at high temperatures. If $\mathrm{Cu}^{2+}$ is forced into another type of coordination environment then the fast relaxation makes observation of the EPR signal challenging or impossible. For $\mathrm{Cu}^{2+}$ substituted for $\mathrm{Zn}^{2+}$ in a tetrahedral site of $\mathrm{ZnO}$ the EPR spectra have been reported revealing very unusual g-values. The spectra can only be observed below $18 \mathrm{~K}$ [24]. As an example of another unusual coordination environment, the EPR spectrum of the hydrated form of $\mathrm{Cu}$ exchanged in the commercial zeolite Linde 13X (FAU framework with very low Si/Al ratio) reveals that a percentage of the copper is in a compressed trigonal bipyramidal coordination environment. Upon dehydration this species disappears and the fraction of normal tetragonal $\mathrm{Cu}^{2+} \mathrm{EPR}$ spectrum increases [25]. 


\section{Zeolite topological features}

All of the frameworks mentioned here (CHA, FAU, MFI, MOR, BEA) contain 6-member ring (6mr) structural features and these are the preferred sites for extra-framework $\mathrm{Cu}^{2+}$ ions if exactly two $\mathrm{Si}$ in the ring are substituted with two Al. In order to keep the discussion short we will limit the discussion of the zeolite topology to have a focus on the occurrence of $6 \mathrm{mr}$.

The CHA and FAU zeolite framework topologies (typically represented by SSZ-13 and zeolite Y, respectively) are, from a crystallographic point of view, very simple structures with only one T-site. These features limit the number of possible exchange sites for extra-framework ions and make these two zeolite topologies very suited for mechanistic studies. They have some similar structural features such as the double 6ring (d6r) composite building units, but other features are different such as the cage and pore sizes. CHA is a small-pore framework where the pore size is dictated by 8-member ring (8mr) windows whereas the FAU framework is a large-pore topology with 12-member ring (12mr) windows. The CHA furthermore consists of cha composite building units, which is considered a cage and is accessible through the 8-ring windows. In FAU there is a larger and accessible super cage that is constructed by connecting sod composite building units. Each of the sod units are connected by $d 6 r$ units and both sod and $d 6 r$ are considered inaccessible for gas molecules due to the small diameter of a 6-ring. Thus in the CHA structure all faces of the $d 6 r$ are exposed to the channel systems and all 6rings are accessible. In comparison only the single 6-ring (s6r) on the face of the sod unit is exposed to the channel system in FAU. Ion exchanged Cu cations may, however, penetrate through the s6r during calcination and subsequent rehydration treatments and thereby access the $6 \mathrm{mr}$ of a $d 6 r$ unit.

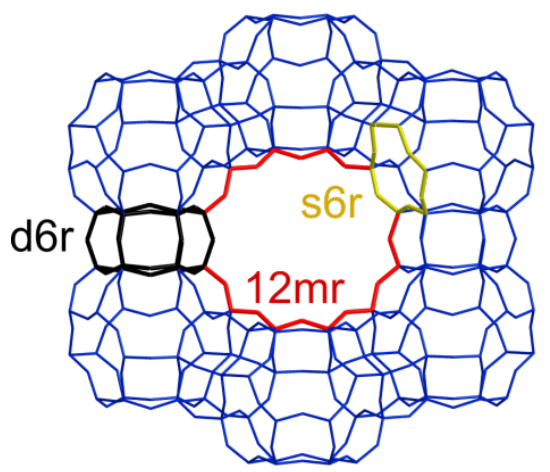

FAU

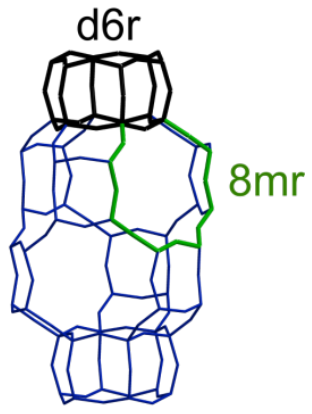

$\mathrm{CHA}$

Fig. 2 Structures of the FAU and CHA topology that both contain double six rings (black, d6r). The single six ring (s6r) in FAU is marked in yellow. The rings defining the largest pores in each topology are marked as well. Red for the 12 membered ring in FAU and green for the 8 membered ring in CHA. 
MFI and MOR (typically represented by ZSM-5 and mordenite, respectively) have an overall lower symmetry and many different T-sites compared to the CHA and FAU topologies. For MOR the $6 \mathrm{mrs}$ are quite bent and all face the large channels defined by 12-rings. In MFI similar $6 \mathrm{mr}$ are present in the channels defined by 10-rings. In both framework topologies a slightly bent $6 \mathrm{mr}$ that have a single $\mathrm{T}$-site bridging the middle of the ring are present. These sites can host a $\mathrm{Cu}^{2+}$. The possible exchange positions especially in MFI have been recently reviewed [26] and a thorough discussion is beyond the scope of this work. A useful view of these $6 \mathrm{mr}$ sites in MFI and MOR showing the bridge above the bent $6 \mathrm{mr}$ can be seen in Fig. 7 of [27].

In BEA a more flat $6 \mathrm{mr}$ face the individual large channels defined by 12-rings. The channel system in the individual polymorphs consists of straight channels. *BEA is furthermore complicated by two different polymorphs and a high number of structural defects.

\section{EPR of Cu-zeolites}

\subsection{Hydrated Cu-zeolites}

All zeolite materials with $\mathrm{Si} / \mathrm{Al}$ ratios relevant for $\mathrm{NH}_{3}$-SCR exposed to ambient conditions will absorb water into the microporous structure. After ion exchange and calcination, copper is present as cations and the framework is negatively charged. Copper is bound to the framework oxygen atoms as ligands and the stiff framework is not able to accommodate the preferences of copper with regards to optimal bond distances and bond angles like it would have been the case for small molecules or ions in solution. Therefore polar water molecules adsorbed into the framework will easily be able to exchange for the framework oxygens and coordinate directly to copper and offers the option for copper to be liberated from strained coordination to framework atoms. The resulting coordination sphere around copper is very similar to the one observed for copper in aqueous solution and can be described as tetragonally elongated 5- or 6-coordination. In large pores or cavities of the zeolites there is enough room for these complexes to have free rotation or to change the elongation axis freely on the timescale of an EPR experiment. Accordingly, the room temperature EPR spectra of the hydrated Cu-zeolites are dominated by an isotropic species which have very similar spin Hamiltonian parameters to the ones of typical species found in aqueous solution such as $\left[\mathrm{Cu}\left(\mathrm{H}_{2} \mathrm{O}\right)_{6}\right]^{2+}$ or $\left[\mathrm{Cu}\left(\mathrm{H}_{2} \mathrm{O}\right)_{5}(\mathrm{OH})\right]^{+}$, see Fig. 1, right. The hyperfine coupling is unresolved and the coordination sphere of $\mathrm{Cu}$ is fluxional on the time-scale of EPR resulting in a very high line width of the isotropic line. For all of the hydrated zeolites it is centered at $g=2.16-2.17$ [11, 28-32]. A percentage of the hydrated copper cations has somewhat restricted motion and an additional anisotropic signal can be seen for Cu-CHA at RT in Fig. 1 right and in [11, 12, 32]. The relative contribution from the anisotropic signal is higher for lower $\mathrm{Cu} / \mathrm{Al}$ ratio [32].

By very gentle dehydration of $\mathrm{Cu}-\mathrm{CHA}$ (this was performed by exposing the size-fractioned sample to a dry He flow at 200 $\mathrm{mL} / \mathrm{min}$ at room temperature) all of the isotropic copper becomes anisotropic without any significant loss of total EPR signal intensity [12]. This is a strong argument for the difference in the two signals to be due to the degrees of freedom. The 
coordination number and average $\mathrm{Cu}-\mathrm{O}$ bond lengths have not changed and indeed the average of the g-values obtained for the anisotropic species is identical to the g-value of the isotropic species. Slight anisotropic features are also visible for CuMFI and $\mathrm{Cu}-* \mathrm{BEA}[12]$. The manifestation of anisotropic features even in the hydrated state of the zeolites indicate that some movement-restricted $\mathrm{Cu}^{2+}$ exchange sites are quite stable and can compete with the fully hydrated state.

At low temperature (77K) the motion has stopped and an, also typical, anisotropic spectrum is obtained which does not reveal any significant differences between the EPR spectra of $\mathrm{Cu}-\mathrm{FAU}, \mathrm{Cu}-* \mathrm{BEA}$, and $\mathrm{Cu}-\mathrm{MFI}$ that can be assigned to differences in the framework topology. The hydrated Cu-MFI investigated at $77 \mathrm{~K}$ reveals a single type of site with wellresolved parallel features, the perpendicular features, however, are not resolved due to the line width, possible small deviations from a perfect axial coordination and site inhomogeneity. From second order perturbation equations and a simplex least-squares fitting routine Larsen et al. determined the spin Hamiltonian parameters to be $g_{\|}=2.39, A_{\|}=425-428$ MHz, $g_{\perp}=2.07$ and small $A_{\perp}$ (Table 1) [33], which is in good agreement with those determined by others [34, 35]. They assign this to copper species close to the channel intersection. For hydrated $\mathrm{Cu}-* \mathrm{BEA}$ and $\mathrm{Cu}-\mathrm{CHA}$ the immobilized spectra at respectively $120 \mathrm{~K}$ and $155 \mathrm{~K}$ are very similar to that of Cu-MFI with $g_{\|}=2.398, A_{\|}=460 \mathrm{MHz}$ for Cu-*BEA [19] and $g_{\|}=2.394, A_{\|}=439 \mathrm{MHz}$ for Cu-CHA [32].

Conesa and Soria investigated Cu-FAU at low copper loading and found that it was in this case possible to distinguish between two $\mathrm{Cu}$ sites in the hydrated zeolite at low temperature. Both sites are listed in Table 1. [28].

Larsen et al. showed that the observable EPR spectrum of $\mathrm{Cu}^{2+}$ in the investigated hydrated zeolite samples at ambient conditions correspond to the total copper content measured by elemental analysis [33]. This means that all copper is present as EPR active tetragonally coordinated monomeric complexes. Others have also confirmed this observation on other zeolite samples [11, 30, 32]. This observation can be utilized extensively in catalyst research of hydrophilic Cu-zeolites, since the hydrated state is the starting point of all ex situ, in situ or operando experiments and the knowledge of the EPR signal intensity at this point will enable quantification of the EPR active copper species, e.g. throughout an entire in situ experiment.

\subsection{Dehydrated Cu-zeolites}

The information on the zeolites obtainable from EPR on fully hydrated Cu zeolites is limited and not representative of the copper coordination under relevant catalytic conditions at higher temperatures. It is also not a well-defined material, since the water content may vary with laboratory temperature and humidity. After performing dehydration procedures on the materials the $\mathrm{Cu}$ EPR signal reveals information about the new coordination of $\mathrm{Cu}$, which is relevant since the materials are typically catalytically active at temperatures where the materials become dehydrated. EPR has higher sensitivity and resolution at low temperatures and therefore it can be an advantage in the assignment of species if the material is first dehydrated at high temperatures and then investigated spectroscopically under dry conditions at low temperatures. Caution 
should be taken not to base conclusions on low temperature spectra alone though, since some species may be stable only at low temperatures and not at the catalytically relevant temperatures.

Table 1 Spin Hamiltonian parameters for $\mathrm{Cu}^{2+}$ species in five different zeolites: Cu-FAU, Cu-*BEA, Cu-MOR, Cu-MFI and Cu-CHA in the hydrated and dehydrated state of the zeolite.

\begin{tabular}{|c|c|c|c|c|c|c|c|c|}
\hline & & ydrated & & & Dehydra & & & \\
\hline & & temperature & & Roc & ow temperature & & High temper & \\
\hline CU-FAU & $\begin{array}{l}\mathbf{N}_{2}(\mathbf{l}) \text { temp. } \\
g_{\|}{ }^{1}=2.416 \\
A_{\|}{ }^{1}=408 \mathrm{MHz} \\
g_{\perp}{ }^{1} \simeq 2.07\end{array}$ & $\begin{aligned} g_{\|}^{2} & =2.385 \\
A_{\|}^{2} & =459 \mathrm{MHz} \\
g_{\perp}^{2} & \simeq 2.07\end{aligned}$ & [28] & $\begin{array}{l}g_{\|}{ }^{1}=2.3 \\
A_{\|}{ }^{1}=510 \mathrm{MHz} \\
g_{\perp}{ }^{1}=2.07\end{array}$ & $\begin{array}{l}g_{\|}^{2}=2.38 \\
A_{\|}^{2}=415 \mathrm{MHz} \\
g_{\perp}^{2}=2.07\end{array}$ & {$[36]$} & & \\
\hline Cu-*BEA & $\begin{array}{l}120 \mathbf{K} \\
g_{\|}=2.403 \\
A_{\|}=432 \mathrm{MHz} \\
g_{\perp}=2.083\end{array}$ & & [19] & $\begin{aligned} g_{\|} & =2.314 \\
A_{\|} & =520 \mathrm{MHz} \\
g_{\perp} & =2.070 \\
A_{\perp} & =33 \mathrm{MHz}\end{aligned}$ & & [19] & $\begin{array}{l}\mathbf{6 7 3 \mathbf { K }} \\
g_{\|}=2.320 \\
A_{\|}=480 \mathrm{MHz} \\
g_{\perp}=2.067 \\
A_{\perp}=9 \mathrm{MHz}\end{array}$ & [19] \\
\hline Cu-MOR $^{\text {a }}$ & $\begin{array}{l}120 \mathbf{~ K} \\
g_{\|}=2.40 \\
A_{\|}=432 \mathrm{MHz} \\
g_{\perp}=2.08\end{array}$ & & {$[18]$} & $\begin{array}{l}120 \mathbf{~ K} \text { after } 250{ }^{\circ} \mathbf{C} \\
g_{\|}{ }^{1}=2.27 \\
A_{\|}{ }^{1}=573 \mathrm{MHz} \\
g_{\perp}{ }^{1}=2.09 \\
A_{\perp}{ }^{1}=54-126 \mathrm{MHz}\end{array}$ & $\begin{array}{l}g_{\|}^{2}=2.32 \\
A_{\|}^{2}=507 \mathrm{MHz} \\
g_{\perp}^{2}=2.07 \\
{A_{\perp}}^{2}=27-66 \mathrm{MHz}\end{array}$ & [37] & & \\
\hline Cu-MFI & $\begin{array}{l}120 \mathbf{K} \\
g_{\|}=2.385 \\
A_{\|}=449 \mathrm{MHz} \\
g_{\perp}=2.084\end{array}$ & & [19] & $\begin{array}{l}g_{\|}{ }^{1}=2.270 \\
A_{\|}{ }^{1}=549 \mathrm{MHz} \\
g_{\perp}{ }^{1}=2.073 \\
A_{\perp}{ }^{1}=10 \mathrm{MHz}\end{array}$ & $\begin{array}{l}g_{\|}^{2}=2.32 \\
A_{\|}{ }^{2}=520 \mathrm{MHz} \\
g_{\perp}{ }^{2}=2.055 \\
{A_{\perp}}^{2}=9 \mathrm{MHz}\end{array}$ & [19] & $\begin{array}{l}\mathbf{6 7 3 \mathbf { K }} \\
g_{\|}=2.324 \\
A_{\|}=474 \mathrm{MHz} \\
g_{\perp}=2.067 \\
A_{\perp}=24 \mathrm{MHz}\end{array}$ & [19] \\
\hline Cu-CHA & $\begin{array}{l}155 \mathbf{~ K} \\
g_{\|}=2.394 \\
A_{\|}=439 \mathrm{MHz} \\
g_{\perp} \simeq 2.07 \\
\end{array}$ & & {$[32]$} & $\begin{array}{l}g_{\|}{ }^{1}=2.325 \\
A_{\|}{ }^{1}=487 \mathrm{MHz} \\
g_{\perp}{ }^{1} \simeq 2.07\end{array}$ & $\begin{array}{l}g_{\|}^{2}=2.358 \\
A_{\|}^{2}=464 \mathrm{MHz} \\
g_{\perp}^{2} \simeq 2.07\end{array}$ & {$[12]$} & & \\
\hline
\end{tabular}

${ }^{a}$ References [18, 37, 38], agree on the parameters for signal 2 in the dehydrated Cu-MOR. [18] have different parameters for the other site and [38] only report one site. Here the values of the $\mathrm{Cu}$ species from [37] are given, since the spectrum has an overall simpler appearance and is not complicated by a possible third species as in [18]. The values from [18] are given for the spectrum of the hydrated Cu zeolite since [37] does not report a spectrum of hydrated Cu-MOR.

Peden et. al. and Borfecchia et. al. report that the loss of water during dehydration of $\mathrm{Cu}-\mathrm{CHA}$ typically reaches a plateau at 220-250 ${ }^{\circ} \mathrm{C}$. [1, 39] This temperature is sufficiently low that disturbance of covalent framework bonds and mobility of copper and alumina species is negligible. Upon dehydration, the spin Hamiltonian parameters of all the copper species in the zeolites change substantially and the EPR intensity decreases. The decrease in EPR intensity can be up to 65-75 \% [19]. This is discussed in section 5.4.

$\mathrm{NH}_{3}$-SCR is the catalytic reaction relevant for these investigations and the response of the zeolites under $\mathrm{NH}_{3}-\mathrm{SCR}$ conditions will be different from the response during the dehydrations. As an example of this it has been shown Cu becomes quite mobile even at relatively low temperatures under reducing $\mathrm{NH}_{3}$-SCR conditions [40], whereas the siting of $\mathrm{Cu}$ is very 
stable during simple dehydrations and may not reach the energy minimum positions. In general, the distribution of the copper ions in the zeolite framework after dehydration is influenced by multiple factors including the $\mathrm{Si} / \mathrm{Al}$ ratio, the zeolite synthesis method, the metal exchange method, the presence of other cations and the pretreatment of the zeolite. Therefore, $\mathrm{Cu}$ zeolites synthesized by different groups may contain different $\mathrm{Cu}$ species and hence caution is important when comparing characterization results between different contributions in the field.

In the following the $\mathrm{Cu}$ species giving well-defined $\mathrm{Cu}^{2+} \mathrm{EPR}$ signals in the different zeolites after dehydration treatments at elevated temperatures and, in some cases, vacuum treatments are discussed.

\subsubsection{Cu-FAU}

$\mathrm{Cu}-\mathrm{FAU}$ has been thoroughly investigated by EPR by several groups. Conesa \& Soria characterized the Cu-species in $\mathrm{Cu}-$ FAU during the dehydration using EPR. They found 5 different $\mathrm{Cu}$-species during dehydration in vacuum at temperature between $25-600{ }^{\circ} \mathrm{C}$ and showed the stepwise dehydration of $\mathrm{Cu}$ during consecutive removal of water molecules [28]. The hydrated $\mathrm{Cu}(\mathrm{II})$-species goes from a six-coordinate fully hydrated state to coordination with 3 water molecules and 3 framework oxygens, $\mathrm{O}_{\mathrm{F}}$. In the next step one water molecule is lost resulting in an almost square pyramidal coordination, and finally 4-coordination in an almost tetrahedral coordination environment with one water molecule and three lattice oxygens is suggested. The latter species is not EPR active, which was explained by Conesa and Soria to be due to the water molecule coordinating close to the approximate $\mathrm{C}_{3}$ axis of the coordination complex formed by $\mathrm{Cu}$ and the three framework oxygens. As outlined above this will result in ground state having a close-lying excited state, and the spin-lattice relaxation time $T_{1}$ will be very short making the $\mathrm{Cu}^{2+}$ undetectable by EPR due to a severe broadening of the absorption line. This is supported by the observation of retained paramagnetism of the sample at this temperature [28]. Losing the last water molecule will allow $\mathrm{Cu}^{2+}$ to move into the plane of the $6 \mathrm{mr}$. Displacement of the $\mathrm{Cu}$ towards the most negatively charged lattice oxygens breaks the 3-fold symmetry and result in a larger $T_{1}$, making the $\mathrm{Cu}$ EPR active again. After complete dehydration Cu-FAU EPR spectra show 2 distinct copper sites with $g_{\|}{ }^{1}=2.33, A_{\|}{ }^{1}=510 \mathrm{MHz}, g_{\|}{ }^{2}=2.38$ and $A_{\|}{ }^{2}=415$ $\mathrm{MHz}$, see Table 1.[36] Other workers also find these two Cu EPR signals and report similar spin Hamiltonian parameters (within \pm 0.02 for g-values and within $\pm 50 \mathrm{MHz}$ for A-values).[41] Pierloot et al. argument from EPR and DFT that the two sites giving different EPR spectra in dehydrated $\mathrm{Cu}$-FAU both correspond to two different types of $\mathrm{Cu}^{2+}$ in $2 \mathrm{Al}$ sites in the $6 \mathrm{mr}$. In both cases $\mathrm{Cu}$ is positioned away from the trigonal axis of FAU [36]. The difference in the spin Hamiltonian parameters between the two types of sites is due to which of the 6 oxygens in the ring are closest and therefore which type of geometric deviation from tetragonal symmetry is present, see Scheme 1. Pierloot et. al. did not argument for which sites were the more stable ones or whether the $6 \mathrm{mr}$ were part of a s6r or d6r, see Fig. 2, since the model used for the theoretical investigation only consisted of a single $6 \mathrm{mr}$. Later Seo et. al used single-crystal X-ray diffraction techniques to prove that after dehydration the $\mathrm{Cu}^{2+}$ are distributed in the $6 \mathrm{mr}$ of both the d6r and s6r for a material with $\mathrm{Si} / \mathrm{Al}=1.56$ [42]. The particular sitings of $\mathrm{Cu}$ in the $6 \mathrm{mr}$ depending on the different $\mathrm{Al}$ distributions are not resolved in the X-ray experiment. 


\subsubsection{Cu-MFI}

Kucherov et. al. showed that after activation in $\mathrm{O}_{2}$ flow at $500{ }^{\circ} \mathrm{C}$; Cu-MFI show two distinct $\mathrm{Cu}^{2+}$ hyperfine patterns with $g_{\|}{ }^{1}=2.27, A_{\|}{ }^{1}=556 \mathrm{MHz}$ and $g_{\|}{ }^{2}=2.32, A_{\|}{ }^{2}=500 \mathrm{MHz}$. These two species were assigned to isolated $\mathrm{Cu}^{2+}$ ions in distorted (5-coordinate) square pyramidal and distorted (4-coordinate) square planar environment, respectively [30]. The MFI zeolite have a much more complex structure than FAU, and cation sites are positioned in combinations of $5 \mathrm{mr}$ and $6 \mathrm{mr}$ making structural assignments rather difficult [43]. Groothaert et al. made progress towards assigning the two copper species using a combination of DFT and EPR [44]. Signal 2 with $g_{\|}{ }^{2}=2.32$ was assigned to $\mathrm{Cu}^{2+}$ in $2 \mathrm{Al} 6 \mathrm{mr}$. Signal 1 with $g_{\|}{ }^{1}=2.27$ was assigned to $\mathrm{Cu}^{2+}$ with only one $\mathrm{Al}$ in the $6 \mathrm{mr}$ ring and charge compensation obtained by an $\mathrm{Al}$ tetrahedron straddling the middle of the ring. With increasing copper content the site corresponding to signal 2 is the first species to appear and then the site corresponding to signal 1 . The site corresponding to signal 1 was observed to be more easily reduced by hydrogen. At high loadings the amount of species with EPR signal 1 is lower. This was explained by the formation of an EPR silent $\mathrm{Cu}^{2+}$ species by coordination of extra-framework oxygen for charge compensation [44]. Progress was also made in this work assigning EPR signal 1 and 2 to particular sites in dehydrated Cu-MFI, but due to the complicated structure it is likely that a distribution of different sites contributes to the total EPR signal. Indeed a splitting in the hyperfine lines of signal 2 was sometimes observed in experiments with high resolution.

\subsubsection{Cu-MOR}

For $\mathrm{Cu}-\mathrm{MOR}$ two types of EPR signal is found after dehydration $[37,45,46]$ with roughly the same values as for Cu-MFI and with the same assignment. Other groups reports a more complicated distribution of species in a Cu-MOR material [18] whereas others could only discern the species with the strongest signal [38]. All agree that the Cu site corresponding to signal 2 is dominant at low concentrations of $\mathrm{Cu}$ and is therefore assumed to be more stable. The $\mathrm{Cu}$ site corresponding to signal 1 is also observed to be more easily reduced in a hydrogen temperature programmed reduction (TPR) experiment [37].

\subsubsection{Cu-*BEA}

For $\mathrm{Cu}-{ }^{*} \mathrm{BEA}$ only one type of species is distinguishable in the dehydrated zeolite. The parameters are similar to that of signal 2 in Cu-MFI and Cu-MOR and as signal 1 in Cu-FAU and Cu-CHA. It is assigned to $\mathrm{Cu}^{2+}$ in distorted square planar coordination in a $6 \mathrm{mr}$ site [19]. Interestingly it was shown in [12] that the loss of EPR signal intensity upon dehydration of the hydrated $\mathrm{Cu}$ zeolite follows $\mathrm{Cu}-\mathrm{CHA}$ and $\mathrm{Cu}-\mathrm{MFI}$ with similar $\mathrm{Si} / \mathrm{Al}$ ratios until $250{ }^{\circ} \mathrm{C}$, but that at higher temperature the signal intensity comes back to a much higher extent. The regain of signal intensity is slow and the results depend on the 
temperature and exposure time indicating that $\mathrm{Cu}$ mobility during dehydration is important and more facilitated than in the zeolites with more narrow pores, Cu-MFI and Cu-CHA.

\subsubsection{Cu-CHA}

By EPR Cu-CHA shows two major and one minor species after dehydration. The major species can be described by the two sets of spin Hamiltonian parameters: $g_{\|}{ }^{1}=2.325, A_{\|}{ }^{1}=487 \mathrm{MHz}$ and $g_{\|}{ }^{2}=2.358, A_{\|}{ }^{2}=464 \mathrm{MHz}$. The perpendicular gvalues for the two species are both $2.07 \pm 0.015$, but the precise values and the difference between the two could net be determined du to overlap in this region. The value for $A_{\perp}$ is not well determined for either species, but is $<50 \mathrm{MHz}$. The two species are both assigned to $\mathrm{Cu}^{2+}$ in distorted tetragonal planar coordination available in 6mr's with $2 \mathrm{Al}$ [12]. Both parameters sets also fit well with coordination to 4 oxygen donors [16, 17]. It is found by quantification of the $\mathrm{Cu}^{2+}$ signal in $\mathrm{Cu}-\mathrm{CHA}$ that in fact all available $2 \mathrm{Al} 6 \mathrm{mr}$ sites, given the assumption of a statistical distribution of $\mathrm{Al}$ sites [47] are occupied with $\mathrm{Cu}^{2+}[12]$.

At room temperature a third species is observed on Cu-CHA with the EPR parameters $g_{\|}{ }^{2}=2.388$ and $A_{\|}{ }^{2}=530 \mathrm{MHz}$. This species only accounts for a minor percentage $(<5 \%)$ of the total copper and cannot be observed at high temperature (likely due to lower resolution). This was assigned to copper in a tetragonal 5-coordination (square pyramidal) where the $\mathrm{Cu}-\mathrm{O}$ distances are closer to the usual preferences for $\mathrm{Cu}^{2+}$. This is not found in the ideal CHA structure, and is closer to the values found for hydrated 5- or 6-coordinate $\mathrm{Cu}^{2+}$ [12]. For CHA only one type of $6 \mathrm{mr}$ is available in contrast to FAU and the assignment of the two major species in Cu-CHA should be more straightforward. In CHA two different 2Al 6mr sites arise when the two $\mathrm{Al}$ are placed differently in the $6 \mathrm{mr}$, either opposite each other with two $\mathrm{Si}$ in between (S-A1) or with only one Si between (S-A2), see Scheme 1. Löwensteins rule preclude neighboring Al so these two options are the only ones. Computational analysis have been used to predict the coordination of $\mathrm{Cu}^{2+}$ in the two cases: The investigations by different groups agree that $\mathrm{Cu}^{2+}$ in S-A2 has three short and one long $\mathrm{Cu}-\mathrm{O}$ bond $[13,39,48] . \mathrm{Cu}^{2+}$ in S-A1 is more difficult to pin down and has several energetic minima. It has been reported to be straddling the center of the ring with $4 \mathrm{Cu}-\mathrm{O}_{\mathrm{F}}$ bonds of similar lengths in some reports, that however did not agree on the particular oxygens participating $[13,48]$ and to be in a position very similar to the one of $\mathrm{Cu}^{2+}$ in S-A2 [49]. Actually the results from EPR may help to solve this discussion once the assignment of the EPR signals is secure. The attempts at this are touched upon in the following section.

\subsection{Assignment of EPR spectra of $\mathrm{Cu}^{2+}$ in $6 \mathrm{mr}$ sites}

The spin Hamiltonian parameters of the different $\mathrm{Cu}$ species given in Table 1 can be plotted in a Blumberg-Peisach plot, see Fig. 3 [16]. A Blumberg-Peisach plot including a range of $\mathrm{Cu}$ zeolite materials was also given by Carl and Larsen [18, 19]. The values for Cu-MOR and Cu-*BEA in Fig. 3 are not coinciding with some of the points in these publications since errors were identified in conversion of the hyperfine parameters, $A_{\|}$from field units to energy units of a literature data in [19] and 
in the tabulated value for the hyperfine parameters of dehydrated $\mathrm{Cu}$-*BEA in [38]. The revised plot reveals that the values found in dehydrated zeolites line up very well for all $\mathrm{Cu}$ zeolites - including $\mathrm{Cu}-\mathrm{CHA}$. In the original Blumberg-Peisach plots the position on the line correlates strongly with the charge on the $\mathrm{Cu}$ coordination entity in such a way that given the same identity and number of donor atoms, the more negatively charged coordination environments are found in the lower right end of the line and the more positive coordination environments are found in the upper left end of the line. This is also the case here. The high Al FAU materials are the only ones that can provide a site with a relatively high negative charge and one Cu-FAU site is at the lower right end of the line. On the other hand Cu-MFI and Cu-MOR are the only ones that have the option to have $\mathrm{Cu}$ in a $6 \mathrm{mr}$ with one $\mathrm{Al}$ in the $6 \mathrm{mr}$ and a second $\mathrm{Al} \mathrm{T}$-site straddling the ring [27]. This coordination environment should give an overall less negatively charged perturbation of the spin-bearing $d_{x^{2}-y^{2}}$ orbital. The site with parameters in the higher left part of the line is indeed assigned to this site as outlined below [37, 44]. For Cu-CHA both set of parameters fall in the middle of the trend line.

The parameters of all hydrated $\mathrm{Cu}$ zeolites (open symbols in Fig.3) cluster at values slightly above and to the left of the trend line for sites in the dehydrated materials. This is due to an overall higher coordination number around $\mathrm{Cu}$ and a different ligand donor profile for water compared to the framework atoms in the dehydrated Cu zeolite materials.

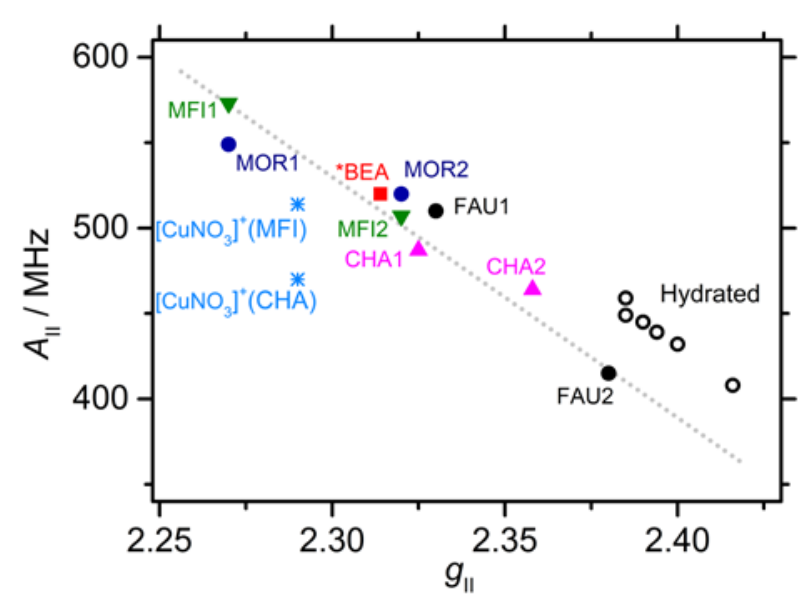

Fig. 3 Blumberg-Peisach plot for the different EPR active $\mathrm{Cu}^{2+}$ species compiled in Table 1. The spin Hamiltonian parameters of dehydrated $\mathrm{Cu}$ zeolites measured at room temperature or below are given with closed symbols. The dotted line is added as a guide to the eye. The spin Hamiltonian parameters of hydrated $\mathrm{Cu}$ zeolites measured at low temperatures are given with open symbols. The two $\mathrm{Cu}$ nitrate species that have been reported are marked with blue stars.

$6 \mathrm{mr}$ are found in the structure of FAU, CHA, MFI, MOR and *BEA. For all structures they are the most stable option for $\mathrm{Cu}^{2+}$ providing that $2 \mathrm{Al}$ are available. It results in a distorted square planar coordination for $\mathrm{Cu}^{2+}$ whereas for MFI and MOR there are pockets where $\mathrm{Cu}$ has a relatively close oxygen atom above the plane. The $\mathrm{Cu}-\mathrm{O}$ bond lengths become too long if $\mathrm{Cu}$ is in the center of a regular $6 \mathrm{mr}$ and therefore either some local distortion of the $6 \mathrm{mr}$ is required or $\mathrm{Cu}$ is found to move away from the center [42]. The details of the $6 \mathrm{mr}$ components are different for all three topologies. The challenges for 
$\mathrm{Cu}$ to pull the opposing atoms in the $6 \mathrm{mr}$ ring closer together will differ for the different types of $6 \mathrm{mr}$ and will result in different energy profiles, minimum energy bond lengths and EPR spectra. For some there might even be a temperature controlled equilibrium distribution between positions [49]. The differences are apparent in the experimental and theoretically predicted EPR spectra of $\mathrm{Cu}$ in $6 \mathrm{mr}$ sites and the potential for extracting information is high if the individual EPR signal can be assigned to $\mathrm{Cu}$ sites found in the structure by e.g. X-ray diffraction.

$\mathrm{Cu}-\mathrm{MOR}$ and $\mathrm{Cu}-\mathrm{CHA}$ have both been investigated with UV-Vis spectroscopy and it was possible to obtain remarkably well-resolved spectral bands in the d-d range of the spectrum [11, 12, 37]. Cu-CHA features 4 distinct bands and Cu-MOR at least 2. The spectra were interpreted in a similar way for both materials: The observed band patterns are suggested to originate in a pattern of three bands from species 1 and three bands from species 2 that are overlapping giving the spectra observed. In both cases the overlapping triplet bands result in two dominant sharp features corresponding to the center of the three bands and smaller satellites to each side. These satellites are more distinct for Cu-CHA than for Cu-MOR. The features from Cu dimers observed in Cu-MOR centered at $22200 \mathrm{~cm}^{-1}$ are not seen in the reported Cu-CHA spectrum. Apart from these two issues the d-d spectra of the two dehydrated materials are very similar. The triplets are centered at $16600 \mathrm{~cm}^{-}$ 1 and $13600 \mathrm{~cm}^{-1}$ for Cu-CHA and at $16750 \mathrm{~cm}^{-1}$ and $13600 \mathrm{~cm}^{-1}$ for Cu-MOR.

The results was used to suggest a correlation between the UV-Vis bands and the EPR signal for Cu-CHA [12]: $\mathrm{Cu}$ in the S$\mathrm{A} 2$ site in CHA was assumed to be coordinated to only $3 \mathrm{O}$, which are also coordinated to an $\mathrm{Al}$ and therefore should be more negatively charged. $\mathrm{Cu}$ in S-A1 was assumed to be coordinated to 4 of these more negatively charged $\mathrm{O}$ atoms. S-A2 is expected to provide the overall least negatively charged donor atoms in the equatorial plane and the lower average ligand field splitting. $\mathrm{Cu}^{2+}$ in S-A2 was therefore assigned to EPR signal 2 and to the triplet being centered at the low value of $13600 \mathrm{~cm}^{-1} . \mathrm{Cu}^{2+}$ in S-A1 was assigned to EPR signal 1 and the triplet being centered at the high value of $16600 \mathrm{~cm}^{-1}$. So far this has not been supported by computational analysis of the spin Hamiltonian parameters or of the splitting of the electronic energy levels in $\mathrm{Cu}-\mathrm{CHA}$. The results from the DFT calculations performed on $\mathrm{Cu}-\mathrm{MOR}$ are in line with the arguments given here for $\mathrm{Cu}-\mathrm{CHA}$ [50]. The electronic spectra of $\mathrm{CuOH}^{+}$species in $8 \mathrm{mr}$ sites may also be contributing this region. This contribution has not yet been identified.

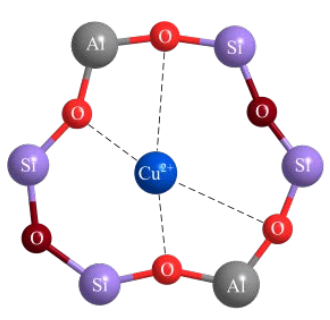

S-A1

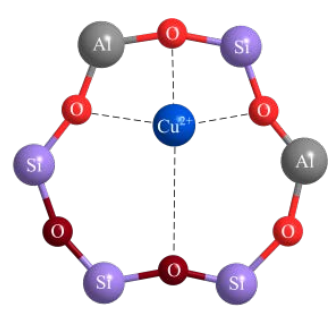

S-A2

Scheme 1 Suggested $\mathrm{Cu}$ positions in $2 \mathrm{Al} 6 \mathrm{mr}$ after dehydration of $\mathrm{Cu}$ - zeolites. The more negatively charged oxygen atoms are red whereas the others are brown. 
For $\mathrm{Cu}-\mathrm{MOR}$ the assignment is the same and in this case the arguments are supported by experiments isolating the sites:[37] The two sites observed by EPR were assigned to the lines in the UV-Vis spectrum such that the EPR signal with high $g_{\|}$ (and low $A_{\|}$) were found to have the low value of the average ligand field splitting and vice versa. The positions in the structure of the sites giving these EPR signals have been discussed [37, 50], and largely follow the assignment of the signals in Cu-MFI that possess similar zeolite building units.

For Cu-MFI a similarly resolved UV-vis spectra have not yet been reported. The EPR signals have been assigned on the basis of DFT calculations of the g-values [44]. EPR signal 1 with the lower $\mathrm{g}_{\|}$-value is assigned to a site with only one $\mathrm{Al}$ in the $6 \mathrm{mr}$ but with a second $\mathrm{Al}$ in the bridge across the middle of the ring. This is named the $\alpha$-site in MFI [27]. EPR signal 2 is assigned to $\mathrm{Cu}$ in a single $6 \mathrm{mr}$ with $2 \mathrm{Al}$ in the ring.

The above arguments for $\mathrm{Cu}-\mathrm{CHA}$ and $\mathrm{Cu}-\mathrm{MOR}$ present a consistent picture, but the assignment between the EPR and UVVis signals and the sittings in the structure cannot say to have been proven completely for any Cu-zeolites at this stage. On the other hand the assignments are well corroborated by the stability of the sites for Cu-MOR [37, 50]. A similar argument can be made for $\mathrm{Cu}-\mathrm{CHA}$, since Gao et. al. find by EPR that at very low $\mathrm{Cu}$ concentrations in a $\mathrm{Cu}-\mathrm{CHA}$ with $\mathrm{Si} / \mathrm{Al}=6$ and $\mathrm{Cu} / \mathrm{Al}=0.032$ only one of the usual two EPR active copper species in Cu-CHA is present [10]. The EPR spectrum of Gao et. al. corresponds perfectly to a single $\mathrm{Cu}^{2+}$ species with parameters identical to signal 2 of $\mathrm{Cu}-\mathrm{CHA}$ in Table 1 . DFT investigations by Göltl et. al. point to the coordination motif of $\mathrm{Cu}$ in S-A2 being the most dominant for $\mathrm{Cu}^{2+}$ [49]. Since the stability of the sites and the predictions from computational analysis agree on the assignment of the EPR signal for Cu-CHA it is reasonable to postulate that EPR signal 2 is indeed originating from $\mathrm{Cu}^{2+}$ in a S-A2 site and signal 1 from $\mathrm{Cu}^{2+}$ in a SA1 site [12].

Interestingly a $\mathrm{Cu}-\mathrm{CHA}$ material prepared by a one-pot synthesis using a $\mathrm{Cu}-\mathrm{TEPA}$ complex as co-template for the CHA zeolite synthesis is found only to have the $\mathrm{Cu}$ site corresponding to EPR signal 2 even though plenty of $\mathrm{Cu}$ is present (Si/Al $=5, \mathrm{Cu} / \mathrm{Al}=0.58$ ) [51]. If the assignment is correct this is suggested to possess a higher population of $\mathrm{Cu}$ in $\mathrm{S}-\mathrm{A} 2$ positions compared to $\mathrm{Cu}-\mathrm{CHA}$ prepared by the normal synthetic procedures.

Schoonheydt et. al. reports the EPR spectrum of a natural occurring chabazite, which has first been ion exchanged with $\mathrm{Na}^{+}$ and then with $\mathrm{Cu}^{2+}$ to the level of $0.15 \mathrm{Cu}$ per unit cell $[52,53]$. Si/Al was not reported but it is assumed to be between 2 and 4 as for other natural occurring chabazite minerals, which will give a $\mathrm{Cu} / \mathrm{Al}$ ratio between 0.03 and 0.06 . The high $\mathrm{Al}$ content of this material changes the structural parameters of the zeolite slightly and it also hosts a high number of $\mathrm{Na}^{+}$ions for charge balance. The EPR spectrum of the dehydrated material revealed two distinct EPR signals: The dominant signal ( $\sim 80 \%$ of the EPR active $\mathrm{Cu}$ ) has the parameters $g_{\|}=2.34$ and $A_{\|}=480 \mathrm{MHz}$. It was assigned to $\mathrm{Cu}^{2+}$ in a $6 \mathrm{mr}$ site in correspondence with the assignment for the synthetic $\mathrm{Cu}-\mathrm{CHA}$ materials, the parameters being in the range between the spin Hamiltonian parameters for CHA signal 1 and 2 in Table 1 . The minor species was reported to have a different set of spin Hamiltonian parameters of $g_{\|}=2.39$ and $A_{\|}=385 \mathrm{MHz}$, which has not been observed in the synthetic chabazites with higher $\mathrm{Si} / \mathrm{Al}$ ratios, but it would also fall on the trend line in Figure 3 close to signal 2 for Cu-FAU (which also had a high 
Al content). It was assigned to a position inside the d6r [52]. The UV-vis spectrum show 3 features in the d-d range at 10750, 13000 and $15000 \mathrm{~cm}^{-1}$ but does not have the feature at $16600 \mathrm{~cm}^{-1}$ and the satellite on the high-energy side observed in the synthetic Cu-CHA. No UV-Vis signal was suggested for the minor species since the suggested coordination environment of $\mathrm{Cu}$ contains an approximate inversion center, which will result in a more Laporte forbidden d-d transition and lower intensity [53]. The assignment of the UV-Vis spectrum corresponds very well to the results and interpretation for the synthetic Cu-CHA [12] if the dominant signal for $\mathrm{Cu}^{2+}$ in the natural chabazite is assigned to $\mathrm{Cu}^{2+}$ in the S-A2 site. The signal assigned to $\mathrm{Cu}^{2+}$ in the less favored S-A1site is not observed. The slight deviation in the spin Hamiltonian parameters of $\mathrm{Cu}^{2+}$ in the S-A2 site (from $g_{\|}=2.358$ to 2.34 and from $A_{\|}=464$ to $480 \mathrm{MHz}$ ) and in the central UV-vis peak (from 13600 to $13000 \mathrm{~cm}^{-1}$ ) are within acceptable levels given the difference in CHA materials.

For $\mathrm{Cu}-\mathrm{MOR}$ and $\mathrm{Cu}-\mathrm{MFI}$ : If the literature assignments of the two EPR signals given above are followed, then only one of the two possible types of $\mathrm{Al}$ distributions in a single $6 \mathrm{mr}$ with $2 \mathrm{Al}$ in the ring, see Scheme 1, are observed. This is signal 2 for $\mathrm{Cu}-\mathrm{MOR}$ and $\mathrm{Cu}-\mathrm{MFI}$. The other EPR signal for these two materials, signal 1, is assigned to another type of $6 \mathrm{mr}$ with an -O-Al-O- bridge above the $6 \mathrm{mr}$. It is not clear at the present time if MOR and MFI only possess one dominant type of Al distribution in the single $6 \mathrm{mr}$; if the $\mathrm{Cu}$ has a preference for the one option due to the less symmetric $6 \mathrm{mr}$ found in MOR and MFI, or if the difference in the EPR spectrum between the two possibilities is not resolved like it is suggested to be in Cu-CHA.

For Cu-FAU a similar comment can be made. Two different $6 \mathrm{mr}$ sites are available in FAU (a single $6 \mathrm{mr}$ on the face of the sod unit and one on the face of the d6r). Therefore in principle it should have four different types of $2 \mathrm{Al}$ sites in $6 \mathrm{mr}$ sites and therefore four different EPR signals if all were present and all were resolved. Under favorable conditions Yu et. al. observe a splitting in EPR signal 1 in Cu-FAU which were interpreted as two separate but similar sites.[41] X-ray investigations indicate that both $6 \mathrm{mr}$ are occupied with $\mathrm{Cu}$ [42]. Therefore it is reasonable to assume that the difference between the two 6mr rings is usually not resolved, but that the EPR signals due to the two different $\mathrm{Al}$ distributions in the rings are resolved. This is in line with the observation for $\mathrm{Cu}-\mathrm{CHA}$, where only one type of $6 \mathrm{mr}$ is present but still two distinct EPR signals are observable.

\subsection{The decrease in EPR signal intensity during dehydration}

The EPR intensity have been proven by many groups to decrease upon dehydration compared to the intensity of the hydrated zeolite [11, 28, 33, 44, 54]. The first example of this was seen for $\mathrm{Cu}-\mathrm{FAU}$ (with 2.2-16 $\mathrm{Cu}^{2+}$ ions per unit cell), which decreases to approximately $55 \%$ of the intensity already after heating at $100-120{ }^{\circ} \mathrm{C}$ in vacuum. At higher temperatures a light increase in intensity is observed and then another drop to approximately $40-60 \%$ at 500-600 ${ }^{\circ} \mathrm{C}$.[55] Conesa and Soria proposed the initial decrease to be due to a change in coordination of the $\mathrm{Cu}^{2+}$ to a near trigonal planar 
environment [55]. The intensity loss has the same temperature dependence for all Cu-zeolites investigated by us at similar dehydration experiments up to about $250{ }^{\circ} \mathrm{C}$ [12]. The specific trigonal site suggested by Conesa and Soria for Cu-FAU cannot be relevant for the other Cu-zeolites but any dehydration pathway will have to involve loss of the tetragonal coordination type for $\mathrm{Cu}$ and this is suggested by Godiksen et. al to be sufficient and that the signal is lost long before the system can be said to approach a true trigonal state [12].

\subsection{1 $[\mathrm{Cu}-\mathrm{OH}]^{+}$}

A [Cu-OH $]^{+}$species was proposed by Valyon and Hall in 1993 on Cu-MFI (with Si/Al = 14.6 and $\mathrm{Cu} / \mathrm{Al}=0.04-0.88$ ) [56]. The $\mathrm{OH}^{-}$group coordinating to $\mathrm{Cu}$ was suggested to arise from the splitting of a water molecule. They proposed that the driving force for the water splitting is that it is a more favorable situation to charge balance two sites separately with monovalent counter ions than having one divalent ion charge balancing two sites, which can be far apart. Larsen et al. also argued for a $[\mathrm{CuOH}]^{+}$site and used this as the first step in their suggestion for the mechanism of the auto-reduction seen for Cu-MFI in inert atmosphere above $200{ }^{\circ} \mathrm{C}$, where $\mathrm{Cu}^{+}$ions can be evidenced [33].

$[\mathrm{Cu}-\mathrm{OH}]^{+}$has been observed on $\mathrm{Cu}-\mathrm{CHA}, \mathrm{Cu}-\mathrm{MFI}$ and $\mathrm{Cu}-{ }^{*} \mathrm{BEA}$ (with $\mathrm{Si} / \mathrm{Al}=11-15$ and $\mathrm{Cu} / \mathrm{Al}=0.42-0.48$ ) after dehydration in $\mathrm{O}_{2} / \mathrm{He}$ by Giordanino et al. through the direct observation of $\mathrm{CuO}-\mathrm{H}$ at $3655 \mathrm{~cm}^{-1}$ and an IR band at $2207 \mathrm{~cm}^{-}$

${ }^{1}$ assigned to $\mathrm{Cu}-\mathrm{OH}{ }^{\cdots} \mathrm{CO}$ in CO-dosing experiments[11]. DFT investigations also suggest a 3-coordinate [Cu-OH] ${ }^{+}$ species as the endpoint of the dehydration for $1 \mathrm{Al}$ sites when copper is not reduced.

$\mathrm{Cu}^{2+}$ in an approximately trigonal planar coordination environment is expected to be EPR silent at ambient or higher temperatures. The argumentation for this is given in details in [12]. The argument is given here in brief form by collecting the general observations given in Section 3 in the case of approximately trigonal planar $\mathrm{Cu}^{2+}$ : This system will have a degenerate ground state which cannot be split efficiently by distorting the angles slightly away from $120^{\circ}$. After a modest change in the bond angles a low-lying excited electronic state is found less than a few thousand wavenumbers away. Vibronic coupling between the ground state and the excited electronic state will allow a fast relaxation of the excited spin state which is only $\sim 0.3$ wavenumbers away at the magnetic field used in X-band EPR. Since the excited spin state is the state reached during an EPR experiment, fast relaxation will be broaden the EPR signal beyond detection at non-cryogenic temperatures. This is a manifestation of the pseudo Jahn-Teller effect.

The situation is even more severe for $[\mathrm{Cu}-\mathrm{OH}]^{+}$than for other 3-coordinate species: The $\mathrm{OH}^{-}$group is light compared to the stiff wall of the framework and a vibration of the $\mathrm{OH}$ group is expected to have a relatively low energy barrier. At the same time the $\mathrm{O}_{\mathrm{F}}-\mathrm{Cu}-\mathrm{OH}$ angle has a strong influence on the energy of the closest excited states. Thus all the requirements for a very fast spin-lattice relaxation are present and we cannot observe an EPR spectrum from [Cu-OH]$]^{+}$.Groothaert et al. investigated a 3-coordinated $[\mathrm{Cu}-\mathrm{OH}]^{+}$species on Cu-MFI with DFT and obtained a calculated value of $g_{\|}=2.45$. This is significantly different from the usual parameters observed for tetragonal $\mathrm{Cu}^{2+}$ and such an EPR signal has never been 
observed on Cu zeolites. This was used to argue that this species could not be present in Cu-MFI [44], or in Cu-MOR [50]. However, as outlined above, EPR cannot detect these species for other reasons and the presence of such species on $\mathrm{Cu}$ zeolites cannot be excluded simply on the basis of the absence of an EPR spectrum.

As mentioned above and in reference [12] we invoke the pseudo Jahn-Teller effect (PJTE) of the [Cu-OH] ${ }^{+}$species to explain most of the loss in EPR intensity (up to 75 \%) seen for Cu-CHA and suggest that it is also relevant for Cu-MFI and other Cu-zeolites that has been dehydrated at moderate temperatures and, importantly, without the use of vacuum. An insitu procedure was developed to use EPR to quantify and distinguish $[\mathrm{Cu}-\mathrm{OH}]^{+}$from other species that are EPR silent, such as $\mathrm{Cu}^{+}$or anti-ferromagnetically coupled $\mathrm{Cu}^{2+}$ dimers. The method uses the different reactivity expected of a [Cu-OH$]^{+}$ species which is significantly more fragile at higher temperatures or under vacuum treatments compared to $\mathrm{Cu}^{2+}$ dimers. An illustration of the experiment and the result is shown in Fig. 4.

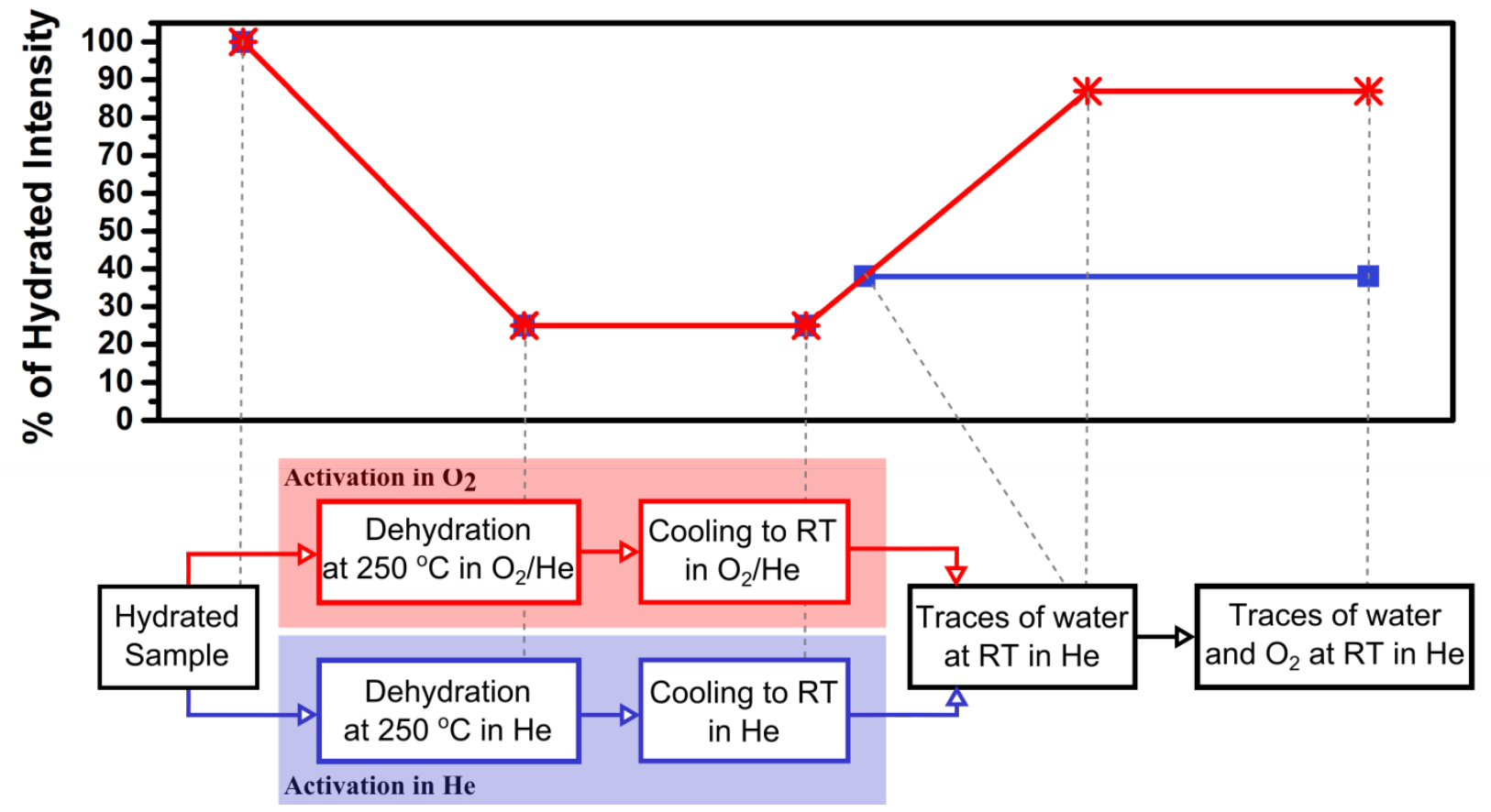

Fig. 4 Bottom: Graphical representation of the in-situ EPR procedure performed while monitoring with EPR. The $\mathrm{O}_{2}$ activation procedure (upper path, red) took place in $20 \% \mathrm{O}_{2}$ and balance He, the other in pure He (lower path, blue) [12]. Top: EPR signal intensity corresponding to the sample having equilibrated under the gas flows given below, where the stars and the red line correspond to the $\mathrm{O}_{2}$ activation and the squares and the blue line to the He activation. Both were performed with a flow of $100 \mathrm{~mL} / \mathrm{min}$ on $20 \mathrm{mg}$ of two identical fractioned $(150-300 \mu \mathrm{m}) \mathrm{Cu}-\mathrm{CHA}$ samples with $\mathrm{Si} / \mathrm{Al}=14$ and $\mathrm{Cu} / \mathrm{Al}=0.46$. The intensity at $250{ }^{\circ} \mathrm{C}$ has been corrected with the Boltzmann equation to be comparable with the intensity at RT. 
An intensity decrease to $25 \%$ was seen immediately after dehydration regardless of the activation gas flow and the EPR spectra of the remaining EPR active species were identical in the two experiments after the first two steps. In step 3 the samples were exposed to traces of water in the He flow at room temperature and at first the EPR spectra of the two samples behaved identically and the intensity increased linearly with time and hydration extent on both samples. After the EPR signal intensity of observable $\mathrm{Cu}$ had increased linearly from 25 to 38\%, the behavior of the two samples diverged despite the experimental conditions being unaltered. The sample dehydrated in pure He levels off at an EPR signal intensity of 38\% relative to the start point, whereas the intensity of the sample dehydrated in an oxygen-containing atmosphere keeps increasing linearly until $87 \%$ of the $\mathrm{Cu}$ is again EPR active. It was argued that these $49 \%$ (= $87 \%$ - $38 \%$ ) of the total amount of copper must be in chemically different states in the two samples after the different pretreatments. It was argued that this percentage became reduced to $\mathrm{Cu}^{+}$during dehydration in He but not during dehydration in $\mathrm{O}_{2} / \mathrm{He}$. Here it remains in the +2 oxidation state as the elusive $[\mathrm{Cu}-\mathrm{OH}]^{+}$species coordinated to a single $\mathrm{Al}$ site. $\mathrm{Cu}^{+}$would not be oxidized to $\mathrm{Cu}^{2+}$ by subsequent treatment with traces of water, but would stay reduced and EPR silent until exposed to an oxidant such as $\mathrm{O}_{2}$. $[\mathrm{Cu}-\mathrm{OH}]^{+}$on the other hand was EPR silent for another reason, namely the approximately trigonal planar coordination. After exposure to water, the coordination environment is again tetragonal and the $\mathrm{Cu}$ becomes EPR active. The small amount of $\mathrm{Cu}$ sites which were EPR silent after the dehydration but did not become reduced by the treatment in He (from 25 to $38 \%$ in Fig. 4), was argued to be due to $\mathrm{Cu}^{2+}$ dimers (or other small copper oligomers together denoted as 'reactive $\mathrm{Cu}_{\mathrm{x}} \mathrm{O}_{\mathrm{y}}$ '), which will easily react with a few water molecules per $\mathrm{Cu}$ giving again EPR active hydrated $\mathrm{Cu}$ monomers. These species have also been suggested by other authors to be present in dehydrated $\mathrm{Cu}-\mathrm{CHA}$ when it is not too dilute in $\mathrm{Cu}$ [57].The mechanism of the auto-reduction of $\mathrm{Cu}$ zeolites has been discussed in the literature for many years. The spectroscopic evidence of up to $49 \%$ of the copper being present as $[\mathrm{Cu}-\mathrm{OH}]^{+}$on $1 \mathrm{Al}$ sites open for the suggestion of a very simple pathway for the auto-reduction and also explains why the reactivity with gas molecules and the spectroscopic response of $\mathrm{Cu}$ in zeolite materials are different depending on the activation procedure. $[\mathrm{Cu}-\mathrm{OH}]^{+}$is suggested to liberate a charge-neutral but unstable $\cdot \mathrm{OH}$ radical by homolytic cleavage of the $\mathrm{Cu}-\mathrm{O}$ bond leaving $\mathrm{Cu}^{+}$[12, 33]. This suggestion has recently been supported by Gao et. al. [58]. This is an unfavorable process which is expected to be increasingly important with higher temperature under flow of inert gas or under vacuum.

The remaining $13 \%$ of the total $\mathrm{Cu}$ (from $87 \%$ to 100\%), does not regain an EPR spectrum until the sample has been exposed to both $\mathrm{O}_{2}$ and water at room temperature and left to equilibrate for several days. It is assigned to non-crystalline polynuclear copper oxide clusters and nanoparticles that were generated during dehydration when $\mathrm{Cu}$ was on the surface of the crystallites or if $\mathrm{Cu}$ in other ways was caught with too few $\mathrm{Al}$ sites in the vicinity.

\subsection{In-situ EPR of Cu-CHA in the SCR reaction}

A consistent reaction cycle for the $\mathrm{NH}_{3}$-SCR reaction has recently been proposed by us and co-workers [8]. The cycle can be regarded as the simplest possible reaction path and involves a single $\mathrm{Cu}$ center connected to the framework in the vicinity 
of a single $\mathrm{Al}$ site. This is relevant for $[\mathrm{CuOH}]^{+}$on an $1 \mathrm{Al} 8 \mathrm{mr}$ site but can also be extended to $\mathrm{Cu}^{2+}$ in a $2 \mathrm{Al}$ site in $6 \mathrm{mr}$ since splitting of water can give $[\mathrm{Cu}-\mathrm{OH}]^{+}$in vicinity of one $\mathrm{Al}$ and a $\mathrm{H}^{+}$in vicinity of the other.

In order to follow the individual steps of the cycle a 4-step procedure was devised. Between each step a short flush with pure helium was performed and the composition of the gasses in the continuous flow was then changed, see Fig. 5. The flow was always $200 \mathrm{~mL} / \mathrm{min}$. (1) The sample was dehydrated for $2 \mathrm{~h}$ in an oxygen containing atmosphere at $250{ }^{\circ} \mathrm{C}$ and the temperature was decreased to $200{ }^{\circ} \mathrm{C}$. (2) Reduction with $\mathrm{NO}(1000 \mathrm{ppm})+\mathrm{NH}_{3}(1200 \mathrm{ppm})$. (3) Oxidation with $\mathrm{NO}$ (1000 ppm) $+\mathrm{O}_{2}(10 \%)$. (4) Treatment with NO (1000 pm). The background-corrected steady-state EPR spectra obtained after step (1), (3) and (4) are shown in Fig.5 as red, blue and purple traces, respectively. In addition the evolution in the spectra between step (1) and (3) and between step (3) and (4) are shown in the insert as the difference spectra obtained after subtracting the spectra in each point.

XANES data had earlier shown that $\mathrm{NO}$ and $\mathrm{NH}_{3}$ together are able to reduce $\mathrm{Cu}^{2+}$ to $\mathrm{Cu}^{+}$at $200{ }^{\circ} \mathrm{C}$ [8], confirming earlier findings [9, 59-61]. The reduction is reflected in the loss of intensity of the $\mathrm{Cu}^{2+} \mathrm{EPR}$ signal during the same treatment, step (1). After reduction a broad signal with unresolved hyperfine structure and an intensity of less than $18 \%$ compared to the intensity of the sample at ambient conditions was observed (not shown here). Upon re-oxidation in $\mathrm{NO}$ and $\mathrm{O}_{2}$ the EPR signal increases from 18 to 59 \%. Signal 1 and 2 both reappear with the same intensity as in the dehydrated sample, see Fig. 5, left. In addition to the sites giving signal 1 and 2, new features appears. The (3) - (1) difference spectra reveals that they are due to the formation of a single new $\mathrm{Cu}$ species (green trace in Fig. 5). The difference spectrum can be simulated using the spin Hamiltonian parameters: $g_{\|}=2.29, A_{\|}=470 \mathrm{MHz}, g_{\perp}=2.06$, $\left(A_{\perp}\right.$ is not well determined but was set to $\left.35 \mathrm{MHz}\right)$. The values differ slightly from those given in ref. [8] due to the more reliable fitting of a single species rather than fitting three different $\mathrm{Cu}$ sites simultaneously in spectrum (2). The new species is assigned to $\left[\mathrm{CuNO}_{3}\right]^{+}$with a bidentate nitrate, see Fig. 5 right panel and is similar to the species formed in Cu-MFI after exposure to NO and $\mathrm{O}_{2}$ [35]. The intensity of the new species corresponds to around $22 \%$ of the total $\mathrm{Cu}^{2+}$ amount. The position of the negative peak in the perpendicular region is very characteristic for the new species. Like for $\left[\mathrm{CuNO}_{3}\right]^{+}$in Cu-MFI [35] it is peaking at a g-value of 2.03 which is more to the right than for any of the other $\mathrm{Cu}^{2+}$ species in the dehydrated $\mathrm{Cu}$ zeolites. Since this feature of the new spectrum is pointy and strong it can be identified even in noisy or low resolution EPR spectra. 


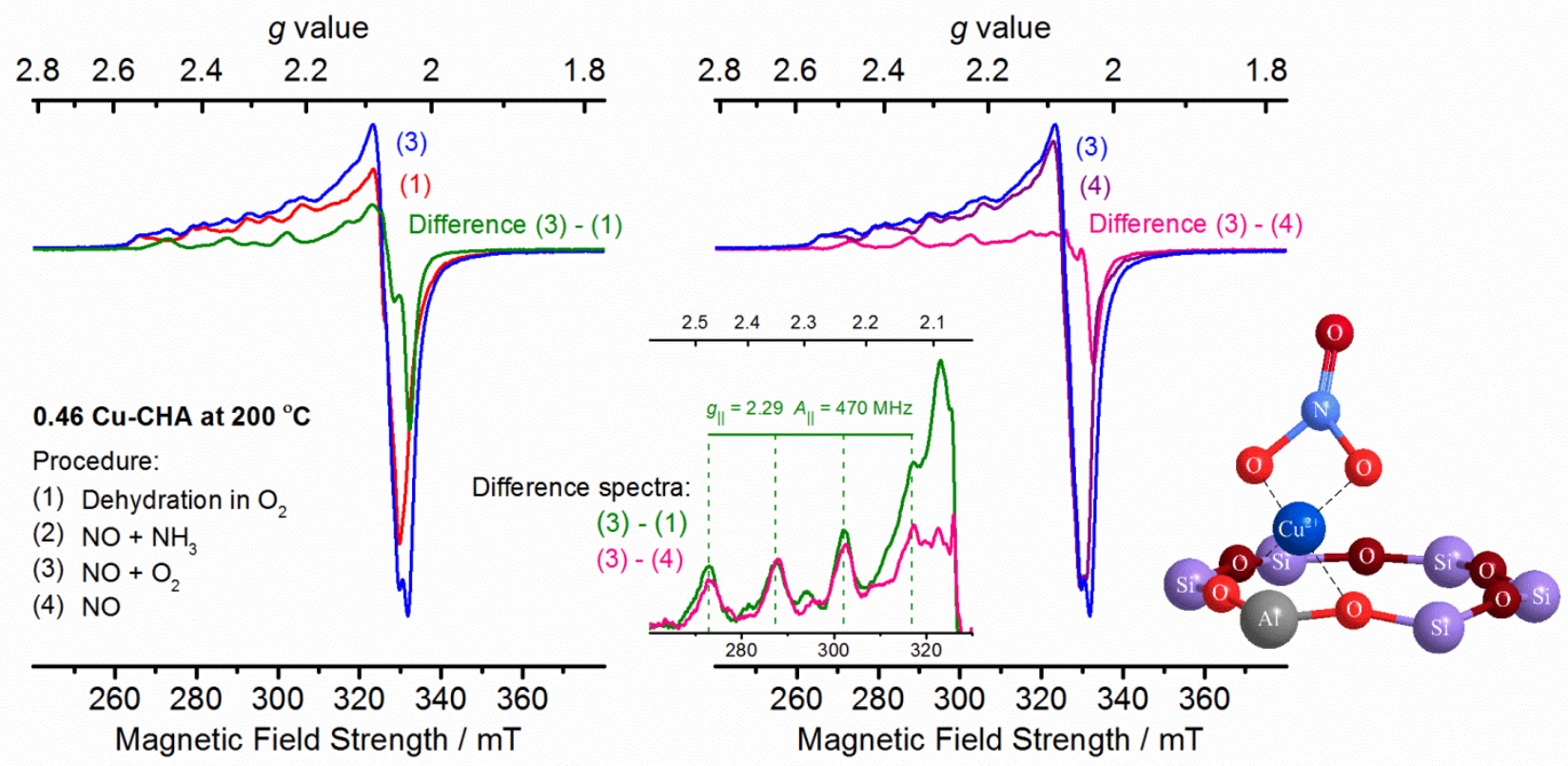

Fig. 5 In-situ X-band EPR spectra at $200{ }^{\circ} \mathrm{C}$ of $\mathrm{Cu}-\mathrm{CHA}(\mathrm{Si} / \mathrm{Al}=14, \mathrm{Cu} / \mathrm{Al}=0.46)$ exposed to SCR relevant gas mixtures [8]. Left: Experimental EPR spectra obtained at $200{ }^{\circ} \mathrm{C}$ after dehydration of the sample for $2 \mathrm{~h}$ in a flow of $\mathrm{O}_{2} / \mathrm{He}$ at $250{ }^{\circ} \mathrm{C}$ (red trace, spectrum 1 ). The same sample was then exposed to a flow of (200 mL/min) of NO (1000 ppm), $\mathrm{NH}_{3}(1200 \mathrm{ppm})$ and balance He for $20 \mathrm{~min}$ followed by a flow of $\mathrm{NO}(1000 \mathrm{ppm})$ and $\mathrm{O}_{2}(10 \%)$ and balance He until steady state (blue trace, spectrum 3). The difference spectrum (green trace) is obtained by simple subtraction of the red spectrum from the blue in every point. Middle: The same sample was then exposed to a flow of NO (1000 ppm) and balance He (purple trace, spectrum 4). The difference spectrum between spectrum 3 and spectrum 4 is shown as the pink trace. Details of the difference spectrum from the left panel, (3)-(1) and from the middle panel, (3)-(4) are plotted for comparison in the insert in the middle panel. Right: Suggested structure for the bidentate nitrate [8, 39].

Step (4) of the procedure was performed in order to follow the nitrate-nitrite equilibrium in the proposed reaction cycle[8]

$$
\left[\mathrm{CuNO}_{3}\right]^{+}+\mathrm{NO} \rightleftharpoons\left[\mathrm{CuNO}_{2}\right]^{+}+\mathrm{NO}_{2}
$$

The signal from the nitrate species disappeared fast and the resulting spectrum, (4) is almost identical to the spectrum of the dehydrated sample, (1) with both signal 1 and signal 2 present. Accordingly, the difference spectrum, (3) - (4) which is pink in Fig. 5 middle panel, shows a $\mathrm{Cu}^{2+}$ spectrum which is almost identical to the difference spectrum between step (1) and (3). This clearly indicates the consumption of the nitrate species upon exposure to NO. In the case reported in Fig. 5, the EPR intensity of the signal decreased with an amount corresponding to $22 \%$ of the total copper content.. The amount of $\mathrm{NO}_{2}$ released from the sample quantified by a chemiluminescence-based $\mathrm{NO}_{\mathrm{x}}$ detector mounted downstream of the sample correlates well with the loss of signal from the nitrate species in the EPR spectra, supporting the proposed equilibrium reaction between nitrate and nitrite [8]. The increase and decrease in EPR intensity upon exposure to $\mathrm{NO}+\mathrm{O}_{2}$ and $\mathrm{NO}$ seems 
to fluctuate to some extent, indicating that the proposed equilibrium between the nitrate and the nitrite species is sensitive towards the specific conditions. In particular the amount of nitrate formed and lost during this type of experiment is dependent on sample history and on the NO content in the $\mathrm{NO}+\mathrm{O}_{2}$ mixture; not all of the $[\mathrm{CuOH}]^{+}$found by the dehydration in-situ procedure shown in Fig.4 (49 \% of the total $\mathrm{Cu}$ for this sample) is found again as EPR active [CuNO $]_{3}^{+}$.

The $\mathrm{Cu}$ nitrite species $\left[\mathrm{CuNO}_{2}\right]^{+}$that should be formed according to the equilibrium reaction, Eqn. (2), is not observed in the EPR spectrum. As emphasized in this work, the existence of a well-defined EPR spectrum of a $\mathrm{Cu}^{2+}$ species at $200{ }^{\circ} \mathrm{C}$ cannot always be expected. A 4-coordinate $\mathrm{Cu}$ species with a bidentate nitrite was found to be the most stable configuration by DFT [8], and is potentially observable by EPR - like the bidentate nitrate. The 3-coordinate species with a monodentate nitrite coordinating on the other hand would not be observable by EPR. Any excited spin state produced in the EPR experiment will relax fast when the coordination is approximately trigonal. If a fast dynamic equilibrium exists between the tetragonal and the trigonal coordination modes the EPR signal will be lost even if the tetragonal $\mathrm{Cu}$ nitrite species is the most stable one.

The nitrate species is not formed at the expense of $\mathrm{Cu}^{2+}$ in the $2 \mathrm{Al} 6 \mathrm{mr}$ sites since signal 1 and signal 2 are both present in undiminished amounts in the EPR spectra after reduction and reoxidation. This indicates that nitrate is not stable on $\mathrm{Cu}$ in these sites under the $\mathrm{NO}+\mathrm{O}_{2}$ flow conditions. It does, however, not rule out the formation of a nitrate intermediate in a reduction and oxidation on a copper site that was originally located in a $2 \mathrm{Al} 6 \mathrm{mr}$ site. In fact a $\left[\mathrm{CuNO}_{3}\right]^{+}$species is not sufficient to charge-balance a $2 \mathrm{Al}$ site and the presence of a cation on the second $\mathrm{Al}$ site allows further reaction. Reduction of the $\mathrm{Cu}^{2+}$ in the $2 \mathrm{Al} 6 \mathrm{mr}$ sites with $\mathrm{NO}$ and $\mathrm{NH}_{3}$ gives a $\mathrm{Cu}^{+}$site associated with one $\mathrm{Al}$ and a $\mathrm{H}^{+}$or $\mathrm{NH}_{4}^{+}$ion on the neighboring Al. After oxidation with $\mathrm{NO}$ and $\mathrm{O}_{2}$ the nitrate is formed, but combination of the $\left[\mathrm{CuNO}_{3}\right]^{+}$with the $\mathrm{H}^{+}$or $\mathrm{NH}_{4}{ }^{+}$allow a pathway where neutral $\mathrm{HNO}_{3}$ or $\mathrm{NH}_{4} \mathrm{NO}_{3}$ can leave the site or decompose. In this way the naked $\mathrm{Cu}^{2+}$ in $2 \mathrm{Al}$ $6 \mathrm{mr}$ is formed and is observed by EPR having spin Hamiltonian parameters identical to those found in the dehydrated sample. Alternatively, the $\left[\mathrm{CuNO}_{3}\right]^{+}$can react with a second NO molecule first according to Eqn. 2 resulting in $\left[\mathrm{CuNO}_{2}\right]^{+}$. In a similar manner this can then subsequently liberate or decompose giving a charge-neutral $\mathrm{HNO}_{2}$ or $\mathrm{NH}_{4} \mathrm{NO}_{2}$ and recover the $\mathrm{Cu}^{2+} 2 \mathrm{Al} 6 \mathrm{mr}$ site.

Another observation from the presented data is that $\mathrm{Cu}^{2+}$ in $2 \mathrm{Al} 6 \mathrm{mr}$ sites were shown to be perfectly stable at $200{ }^{\circ} \mathrm{C}$ in a flow containing $\mathrm{NO}$ at $1000 \mathrm{ppm}$ without change of intensity or spectroscopic features [8]. From this observation the presence of significant amounts of monomeric $\mathrm{Cu}^{+}-\mathrm{NO}^{+}$in the $6 \mathrm{mr}$ sites can be ruled out. These were suggested to result from 1-electron oxidation of $\mathrm{NO}$ by $\mathrm{Cu}^{2+}$ in the $2 \mathrm{Al} 6 \mathrm{mr}$ sites [1, 61].

The link between the spectroscopic parameters and the quantitative information gained from the EPR measurements of both dehydration-rehydration experiments and the SCR reduction-reoxidation experiments demonstrates some of the key advantages of EPR spectroscopy as a useful tool for identification of the species present during in situ conditions for copper containing catalysts. 


\section{Conclusions}

In this mini-review we have reviewed selected parts of the literature on EPR of Cu zeolites and have given plausible suggestions for the structural properties of EPR active $\mathrm{Cu}$ sites observed during zeolite catalyst studies for a number of $\mathrm{Cu}$ zeolites

The preference of extra-framework $\mathrm{Cu}^{2+}$ ions for the $2 \mathrm{Al} 6 \mathrm{mr}$ sites for all zeolite has been confirmed and these are found in all topologies treated here: FAU, CHA, MOR, MFI and *BEA. The empirical relation between the parallel spin Hamiltonian parameters of $\mathrm{Cu}$ species known in the literature as the Blumberg-Peisach plot has been used before on Cu zeolites and the presentation here is largely the same. It has been revised by including the data for Cu-CHA and by correcting a few points in the previous plot. The revised plot reveals how the EPR active sites for all the investigated dehydrated Cu zeolites cluster on a single trend line and how the values for the hydrated zeolites cluster closer together on a second close-lying parallel line.

The recent results for evaluating possible structures for the EPR silent $\mathrm{Cu}$ species in $\mathrm{Cu}-\mathrm{CHA}$ were reviewed. Both $[\mathrm{CuOH}]^{+}, \mathrm{Cu}$ dimers and $\mathrm{Cu}^{+}$are expected to be present in the dehydrated material and to be EPR silent. Of these [CuOH$]^{+}$ and the reactive $\mathrm{Cu}$ dimers or oligomers could be perturbed into EPR active species by controlled water dosing experiments, whereas $\mathrm{Cu}^{+}$remains EPR silent until a suitable oxidant is also present. Neither $\mathrm{O}_{2}$ in a dry environment nor water in an inert atmosphere is able to oxidize $\mathrm{Cu}^{+}$to any of the EPR active $\mathrm{Cu}^{2+}$ sites. Traces of water and $\mathrm{O}_{2}$ together, however, are able to accomplish this at room temperature.

Quantification by EPR signal intensity analysis reveals that a complete coverage of the available 2Al 6mr sites was obtained for $\mathrm{Cu}-\mathrm{CHA}$ samples with a $\mathrm{Cu} / \mathrm{Al}$ ratio of 0.46 . The preference of $\mathrm{Cu}^{2+}$ for the S-A2 site was revealed at lower contents of copper or by different $\mathrm{Cu}-\mathrm{CHA}$ synthesis methods.

When $\mathrm{Cu}-\mathrm{CHA}$ in the fully reduced state is exposed to $\mathrm{NO}$ and $\mathrm{O}_{2}$ together, copper is oxidized and three distinct EPR active $\mathrm{Cu}^{2+}$ species appear. Two of them are already known from the dehydrated $\mathrm{Cu}-\mathrm{CHA}$ and were assigned to $\mathrm{Cu}^{2+}$ in $2 \mathrm{Al} 6 \mathrm{mr}$ sites. The third EPR active site is assigned to $\left[\mathrm{CuNO}_{3}\right]^{+}$in $8 \mathrm{mr}$ sites. It is shown to react easily with a gas flow containing only NO giving again an EPR silent Cu site. The spin Hamiltonian parameters of the suggested nitrate species is found to be displaced from the trend line revealing subtle differences between the coordination provided by a nitrate anion and that of oxygen atoms belonging to the $6 \mathrm{mr}$ of a zeolite framework. It was shown how EPR can provide substantial complementary information to elucidate the resting states for intermediates on the SCR reaction on Cu-CHA and how it is possible to work around the inherent limitation of EPR related to the fast relaxation of some sites. The flexible in-situ EPR setup with controlled gas flows can be used to test hypotheses for the individual steps in the reaction cycle for the SCR reaction.

\section{References}


1. Gao F, Kwak JH, Szanyi J, Peden CHF (2013) Current Understanding of Cu-Exchanged Chabazite Molecular Sieves for Use as Commercial Diesel Engine DeNOx Catalysts. Top Catal 56:1441-1459. doi: 10.1007/s11244-0130145-8

2. Beale AM, Gao F, Lezcano-Gonzalez I, et al. (2015) Recent advances in automotive catalysis for NO x emission control by small-pore microporous materials. Chem Soc Rev 44:7371-7405. doi: 10.1039/C5CS00108K

3. Deka U, Lezcano-Gonzalez I, Weckhuysen BM, Beale AM (2013) Local environment and nature of Cu active sites in zeolite-based catalysts for the selective catalytic reduction of NOx. ACS Catal 3:413-427.

4. EU Commission (2011) COMMISSION REGULATION (EU) No 582/2011 of 25 May 2011. Off J Eur Union L $167: 1$.

5. Meier WM, Olson DH, Baerlocher C (1996) Atlas of zeolite structure types. Zeolites 17:1-230. doi: 10.1017/CBO9781107415324.004

6. Iwamoto M, Hamada H (1991) Removal of nitrogen monoxide from exhaust gases through novel catalytic processes. Catal Today 10:57-71. doi: 10.1016/0920-5861(91)80074-J

7. Kwak JH, Tonkyn RG, Kim DH, et al. (2010) Excellent Activity and Selectivity of Cu-SSZ-13 in the Selective Catalytic Reduction of NOx with NH 3. J Catal 275:187-190.

8. Janssens TVW, Falsig H, Lundegaard LF, et al. (2015) A Consistent Reaction Scheme for the Selective Catalytic Reduction of Nitrogen Oxides with Ammonia. ACS Catal 5:2832-2845. doi: 10.1021/cs501673g

9. Paolucci C, Verma A a., Bates S a., et al. (2014) Isolation of the Copper Redox Steps in the Standard Selective Catalytic Reduction on Cu-SSZ-13. Angew Chemie Int Ed 53:11828-11833. doi: 10.1002/anie.201407030

10. Gao F, Walter ED, Kollar M, et al. (2014) Understanding ammonia selective catalytic reduction kinetics over Cu/SSZ-13 from motion of the Cu ions. J Catal 319:1-14. doi: 10.1016/j.jcat.2014.08.010

11. Giordanino F, Vennestrøm PNR, Lundegaard LF, et al. (2013) Characterization of Cu-exchanged SSZ-13: a comparative FTIR, UV-Vis, and EPR study with Cu-ZSM-5 and Cu- $\beta$ with similar $\mathrm{Si} / \mathrm{Al}$ and $\mathrm{Cu} / \mathrm{Al}$ ratios. Dalton Trans 42:12741-61. doi: 10.1039/c3dt50732g

12. Godiksen A, Stappen FN, Vennestrøm PNR, et al. (2014) Coordination Environment of Copper Sites in Cu-CHA Zeolite Investigated by Electron Paramagnetic Resonance. J Phys Chem C 118:23126-23138. doi: 10.1021/jp5065616

13. Andersen CW, Bremholm M, Vennestrøm PNR, et al. (2014) Location of Cu ${ }^{2+}$ in CHA zeolite investigated by Xray diffraction using the Rietveld/maximum entropy method. IUCrJ 1:382-386. doi: 10.1107/S2052252514020181 
14. Stoll S, Schweiger A (2006) EasySpin, a comprehensive software package for spectral simulation and analysis in EPR. J Magn Reson 178:42-55. doi: 10.1016/j.jmr.2005.08.013

15. Addison AW, Yokoi H (1977) Spectroscopic and Redox Properties of Pseudotetrahedral Copper (II) Complexes. Their Relationship to Copper Proteins. Inorg Chem 16:1341-1349.

16. Peisach J, Blumberg WE (1974) Structural Implications Derived from the Analysis of Electron Paramagnetic Resonance Spectra of Natural and Artificial Copper Proteins. Arch Biochem Biophys 165:691-708.

17. Sakaguchi U, Addison AW (1979) Spectroscopic and Redox Studies of Some Copper(i1) Complexes with Biomimetic Donor Atoms : Implications for Protein Copper Centres. J Chem Soc Dalt Trans 600-608.

18. Carl PJ, Larsen SC (2000) EPR Study of Copper-Exchanged Zeolites : Effects of Correlated g - and A -Strain , Si / Al Ratio , and Parent Zeolite. J Phys Chem B 104:6568-6575.

19. Carl PJ, Larsen SC (1999) Variable-Temperature Electron Paramagnetic Resonance Studies of Copper-Exchanged Zeolites. J Catal 182:208-218.

20. Öpik U, Pryce MHL (1957) Jahn-Teller effect. I. A survey of the static problem. Proc R Soc London A 238:425447.

21. Jahn HA, Teller E (1937) Stability of polyatomic molecules in degenerate electronic states. I. Orbital degeneracy. Proc R Soc London A 161:220-235.

22. Bendix J (2004) Ligfield. Compr Coord Chem 2:673-676.

23. Piligkos S, Bendix J, Weihe H, et al. (2008) A ligand-field study of the ground spin-state magnetic anisotropy in a family of hexanuclear Mn(III) single-molecule magnets. Dalt Trans 2277-84. doi: 10.1039/b718225b

24. Broser I, Schulz M (1969) Elektronenspinresonanz an Kupferdozierten ZnO-Einkristallen. Solid State Commun 7:651-655.

25. Narayana M, Kevan L (1983) Detection of a new trigonal bipyramidal copper species in Cu-CaX zeolite by electron spin resonance and electron spin echo modulation analysis. J Chem Phys 78:3573-3578. doi: 10.1063/1.445184

26. Vanelderen P, Vancauwenbergh J, Sels BF, Schoonheydt RA (2013) Coordination chemistry and reactivity of copper in zeolites. Coord Chem Rev 257:483-494. doi: 10.1016/j.ccr.2012.07.008

27. Dědeček J, Kaucký D, Wichterlová B (2000) Co2+ ion siting in pentasil-containing zeolites, part 3. Co2+ ion sites and their occupation in ZSM-5: A VIS diffuse reflectance spectroscopy study. Microporous Mesoporous Mater 3536:483-494. doi: 10.1016/S1387-1811(99)00244-9 
28. Conesa JC, Soria J (1979) Electron spin resonance of Copper-exchanged Y Zeolites. J Chem Soc Faraday Trans 1 75:291-293.

29. Nicula A, Stamires D, Turkevich J (1965) Paramagnetic Resonance Absorption of Copper Ions in Porous Crystals. J Chem Phys 42:3684-3692. doi: 10.1063/1.1695780

30. Kucherov A, Gerlock J (1994) In-Situ Determination by ESR of the Oxidation State of Copper in Cu-ZSM-5 in Flowing He and O2 up to 500. degree. C. J Phys Chem 98:4892-4894.

31. Kucherov A V, Slinkin AA (1989) Change of Cu(II) Cation Coordination in H-ZSM-5 Channels upon the Sorption of n-Hexane and Xenon: ESR Spectroscopic Evidence. J Phys Chem 93:864-867.

32. Gao F, Walter ED, Karp EM, et al. (2013) Structure-activity relationships in NH3-SCR over Cu-SSZ-13 as probed by reaction kinetics and EPR studies. J Catal 300:20-29. doi: 10.1016/j.jcat.2012.12.020

33. Larsen SC, Aylor A, Bell AT, Reimer JA (1994) Electron Paramagnetic Resonance Studies of Copper IonExchanged ZSM-5. J Phys Chem 98:11533-11540. doi: 10.1021/j100095a039

34. Anderson MW, Kevan L (1987) Study of Cu2+-Doped Zeolite NaH-ZSM-5 by Electron Spin Resonance and Electron Spin Echo Modutation Spectroscopies. J Phys Chem 91:4174-4179.

35. Kucherov A, Gerlock J, Jen H, Shelef M (1995) In situ esr monitoring of the coordination and oxidation states of copper in Cu-ZSM-5 up to $500^{\circ} \mathrm{C}$ in flowing gas mixtures: 1 . Interaction with $\mathrm{He}, \mathrm{O} 2, \mathrm{NO}, \mathrm{NO} 2$ and $\mathrm{H} 2 \mathrm{O}$. Zeolites 15:9-14.

36. Pierloot K, Delabie A, Groothaert MH, Schoonheydt RA (2001) A reinterpretation of the EPR spectra of Cu(II) in zeolites A, Y and ZK4, based on ab initio cluster model calculations. Phys Chem Chem Phys 3:2174-2183. doi: 10.1039/b100531f

37. Vanelderen P, Vancauwenbergh J, Tsai M-L, et al. (2014) Spectroscopy and redox chemistry of copper in mordenite. ChemPhysChem 15:91-99. doi: 10.1002/cphc.201300730

38. Oliva C, Selli E, Ponti A, et al. (1997) FTIR and EPR characterisation of copper-exchanged mordenites and beta zeolites. J Chem Soc Faraday Trans 93:2603-2608. doi: 10.1039/a701477e

39. Borfecchia E, Lomachenko KA, Giordanino F, et al. (2015) Revisiting the nature of $\mathrm{Cu}$ sites in the activated CuSSZ-13 catalyst for SCR reaction. Chem Sci 6:548-563. doi: 10.1039/C4SC02907K

40. Shwan S, Skoglundh M, Lundegaard LF, et al. (2014) Solid-State Ion-Exchange of Copper into Zeolites Facilitated by Ammonia at Low Temperature. ACS Catal 5:16-19. doi: 10.1021/cs5015139 
41. Yu J-S, Kevan L (1990) Temperature dependence of copper(II) migration and formation of new copper(II) species during catalytic propylene oxidation on copper(II)-exchanged Y zeolite and comparison with X zeolite. J Phys Chem 94:7612-7620.

42. Seo SM, Lim WT, Seff K (2012) Crystallographic verification that copper(II) coordinates to four of the oxygen atoms of zeolite 6-rings. Two single-crystal structures of fully dehydrated, largely $\mathrm{Cu} 2+$ exchanged zeolite y (FAU, $\mathrm{Si} / \mathrm{Al}=1.56)$. J Phys Chem C 116:963-974. doi: 10.1021/jp209542x

43. Deka U, Eilertsen EA, Emerich H, et al. (2012) Confirmation of Isolated Cu 2 + Ions in SSZ-13 Zeolite as Active Sites in NH3-Selective Catalytic Reduction. J Phys Chem C 116:4809-4818.

44. Groothaert MH, Pierloot K, Delabie A, Schoonheydt RA (2003) Identification of Cu(ii) coordination structures in Cu-ZSM-5, based on a DFT/ab initio assignment of the EPR spectra. Phys Chem Chem Phys 5:2135-2144. doi: 10.1039/b301120h

45. De Tavernier S, Schoonheydt RA (1991) Coordination of Cu2+ in synthetic mordenites. Zeolites 11:155-163.

46. Kucherov AV, Slinkin AA, Kondrat'ev DA, et al. (1985) Cu2+-cation location and reactivity in mordenite and ZSM-5: e.s.r.-study. Zeolites 5:320-324. doi: 10.1016/0144-2449(85)90166-6

47. Bates SA, Verma AA, Paolucci C, et al. (2014) Identification of the active Cu site in standard selective catalytic reduction with ammonia on Cu-SSZ-13. J Catal 312:87-97. doi: 10.1016/j.jcat.2014.01.004

48. Göltl F, Bulo RE, Sautet P (2013) What Makes Copper-Exchanged SSZ-13 Zeolite Efficient at Cleaning Car Exhaust Gases? J Phys Chem Lett 4:2244-2249.

49. Göltl F, Sautet P, Hermans I (2015) The impact of finite temperature on the coordination of Cu cations in the zeolite SSZ-13. Catal Today http://dx.doi.org/10.1016/j.cattod.2015.10.028. doi: 10.1016/j.cattod.2015.10.028

50. Delabie A, Pierloot K, Groothaert MH, et al. (2001) The siting of $\mathrm{Cu}(\mathrm{II})$ in mordenite: a theoretical spectroscopic study. Phys Chem Chem Phys 4:134-145. doi: 10.1039/b105799p

51. Moreno-González M, Hueso B, Boronat M, et al. (2015) Ammonia-Containing Species Formed in Cu-Chabazite As Per In Situ EPR, Solid-State NMR, and DFT Calculations. J Phys Chem Lett 6:1011-1017. doi: 10.1021/acs.jpclett.5b00069

52. Packet D, Dehertogh W, Schoonheydt RA (1985) Spectroscopy of Cu(II) Coordinated to Lattice Oxygens in Zeolites. In: Drzaj B, Hocevar S, Pevojnik S (eds) Zeolites Synth. Struct. Technol. Appl. Elsevier Science Publishers B.V., Amsterdam, pp 351-358

53. Schoonheydt RA (1993) Transition metal ions in zeolites: Siting and energetics of Cu2+. Catal Rev - Sci Eng 
35:129-168. doi: 10.1081/E-EEE2-120046011

54. LoJacono M, Fierro G, Dragone R, et al. (1997) Zeolite chemistry of CuZSM-5 revisited. J Phys Chem B 5647:1979-1984.

55. Conesa JC, Soria J (1978) Electron spin resonance of undetected copper(II) ions in Y zeolite. J Phys Chem 82:1847-1850.

56. Valyon J, Hall WK (1993) On the preparation and properties of CuZSM-5 catalysts for NO decomposition. Catal Letters 19:109-119. doi: 10.1007/BF00771745

57. Verma AA, Bates SA, Anggara T, et al. (2014) NO oxidation: A probe reaction on Cu-SSZ-13. J Catal 312:179190. doi: 10.1016/j.jcat.2014.01.017

58. Gao F, Wang Y, Washton NM, et al. (2015) Effects of Alkali and Alkaline Earth Cocations on the Activity and Hydrothermal Stability of Cu/SSZ-13 NH 3 -SCR Catalysts. ACS Catal 5:6780-6791. doi:

10.1021/acscatal.5b01621

59. Günter T, Carvalho H, Doronkin DE, et al. (2015) Structural snapshots of the SCR reaction mechanism on Cu-SSZ13. Chem Commun 51:9227-9230. doi: 10.1039/C5CC01758K

60. Kieger S, Delahay G, Coq B, Neveu B (1999) Selective catalytic reduction of nitric oxide by ammonia over CuFAU catalysts in oxygen-rich atmosphere. J Catal 183:267-280. doi: DOI: 10.1006/jcat.1999.2398

61. Kwak JH, Lee JH, Burton SD, et al. (2013) A common intermediate for N2 formation in enzymes and zeolites: sideon Cu-nitrosyl complexes. Angew Chem Int Ed Engl 52:9985-9989. doi: 10.1002/anie.201303498 